\title{
TU/e emonownen

\section{Elucidating the Stability of Single-Chain Polymeric Nanoparticles in Biological Media and Living Cells}

\section{Citation for published version (APA):}

Deng, L., Albertazzi, L., \& Palmans, A. R. A. (2022). Elucidating the Stability of Single-Chain Polymeric Nanoparticles in Biological Media and Living Cells. Biomacromolecules, 23(1), 326-338.

https://doi.org/10.1021/acs.biomac.1c01291

\section{Document license:}

CC BY-NC-ND

DOI:

10.1021/acs.biomac.1c01291

Document status and date:

Published: 10/01/2022

\section{Document Version:}

Publisher's PDF, also known as Version of Record (includes final page, issue and volume numbers)

\section{Please check the document version of this publication:}

- A submitted manuscript is the version of the article upon submission and before peer-review. There can be important differences between the submitted version and the official published version of record. People interested in the research are advised to contact the author for the final version of the publication, or visit the $\mathrm{DOI}$ to the publisher's website.

- The final author version and the galley proof are versions of the publication after peer review.

- The final published version features the final layout of the paper including the volume, issue and page numbers.

Link to publication

\section{General rights}

Copyright and moral rights for the publications made accessible in the public portal are retained by the authors and/or other copyright owners and it is a condition of accessing publications that users recognise and abide by the legal requirements associated with these rights.

- Users may download and print one copy of any publication from the public portal for the purpose of private study or research.

- You may not further distribute the material or use it for any profit-making activity or commercial gain

- You may freely distribute the URL identifying the publication in the public portal.

If the publication is distributed under the terms of Article 25fa of the Dutch Copyright Act, indicated by the "Taverne" license above, please follow below link for the End User Agreement:

www.tue.nl/taverne

Take down policy

If you believe that this document breaches copyright please contact us at:

openaccess@tue.nl

providing details and we will investigate your claim. 


\title{
Elucidating the Stability of Single-Chain Polymeric Nanoparticles in Biological Media and Living Cells
}

\author{
Linlin Deng, Lorenzo Albertazzi, and Anja R. A. Palmans*
}

Cite This: Biomacromolecules 2022, 23, 326-338

Read Online

ABSTRACT: The controlled folding of synthetic polymer chains into single-chain polymeric nanoparticles (SCPNs) of defined size and shape in water is a viable way to create compartmentalized, nanometer-sized structures for a range of biological applications. Understanding the relationship between the polymer's microstructure and the stability of folded structures is crucial to achieving desired applications. Here, we introduce the solvatochromic dye Nile red into SCPNs and apply a combination of spectroscopic and microscopic techniques to relate polymer microstructure to nanoparticle stability in complex biological media and cellular environments. Our experimental data show that the polymer's

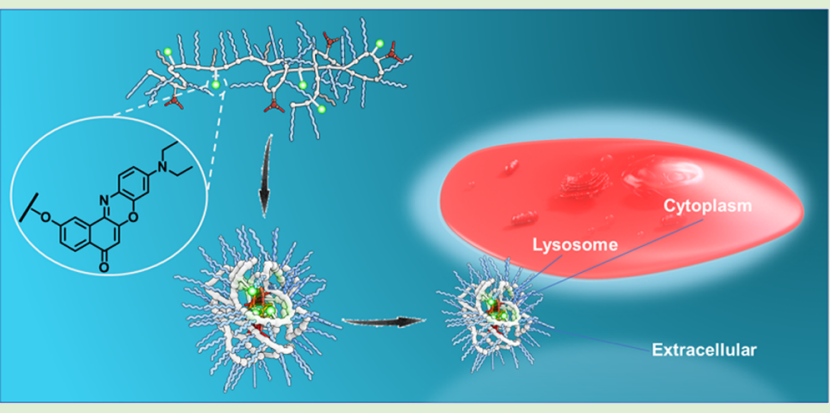
microstructure has little effect on the stability of SCPNs in biological media and cytoplasm of living cells, but only SCPNs comprising supramolecular benzene-1,3,5-tricarboxamide (BTA) motifs showed good stability in lysosomes. The results indicate that the polymer's microstructure is vital to ensure nanoparticle stability in highly competitive environments: both hydrophobic collapse and a structured interior are required. Our study provides an accessible way of probing the stability of SCPNs in cellular environments and paves the way for designing highly stable SCPNs for efficient bio-orthogonal catalysis and sensing applications.

\section{INTRODUCTION}

Nature is a source of inspiration for designing and constructing well-defined macromolecular architectures. ${ }^{1-6}$ By mimicking nature's way of folding polypeptides into proteins, single-chain polymeric nanoparticles (SCPNs) have been developed, which are nanometer-sized objects that form by folding synthetic polymer chains via a combination of hydrophobic and/or directional hydrogen-bonding interactions into an individual and soft nanoparticle with a hydrophobic interior. ${ }^{7}$ Controlling polymer conformations in organic solvents has been studied in great detail, $^{8-12}$ but to enable applications in the biological field, controlling the collapse/folding of polymer chains in an aqueous solution is required. ${ }^{13-15}$ To adapt to the aqueous environment, polymers with amphiphilic properties and comprising randomly distributed hydrophilic and hydrophobic groups are often employed as this microstructure enables the collapse of single-polymer chains into SCPNs in an aqueous solution due to solvophobic interactions. ${ }^{16-19}$ In addition, hydrogen-bonding interactions endow SCPNs with a better controlled organization, ${ }^{20-23}$ making the selection of appropriate groups that trigger intrachain collapse crucial. ${ }^{24-27}$ Due to the directional hydrogen-bonding formation, the flexible polymer chains form nanoparticles with a structured interior, which is similar to polypeptides folding into $\alpha$-helical and $\beta$ sheet conformation. Therefore, a combination of hydrophilic, hydrophobic, and hydrogen-bonding interactions to fabricate SCPNs is a rudimentary approach toward protein mimics.
Additional functional groups introduced to amphiphilic polymers allow nanoparticles to have a variety of functionalities. Owing to their ease of functionalization and small size, water-soluble SCPNs have been explored for a range of applications such as catalysis, ${ }^{28-32}$ drug carriers, ${ }^{33,34}$ nanoreactors, ${ }^{35}$ and imaging agents ${ }^{36,37}$ in an aqueous environment. To function effectively in biological media and in living cells, one major challenge is to guarantee the stability of SCPNs, i.e., that the folded structure is retained in the presence of hydrophobic biological (macro)molecules. The presence of vitamins, amino acids, and a high concentration of glucose in cell culture media may affect how these polymeric assemblies organize their hydrophobic interior. In addition, multiple biomolecular species in living cells were reported to interact with nanoparticles and have an influence on their conformation and functionality. ${ }^{38,39}$ It is well known that serum proteins are able to adsorb onto nanoassemblies and form a protein corona, which directly affects their surface properties and behavior. ${ }^{40-43}$ All of these factors impose challenges on

Received: September 29, 2021

Revised: November 12, 2021

Published: December 14, 2021

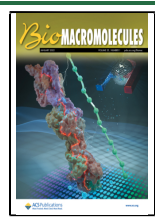




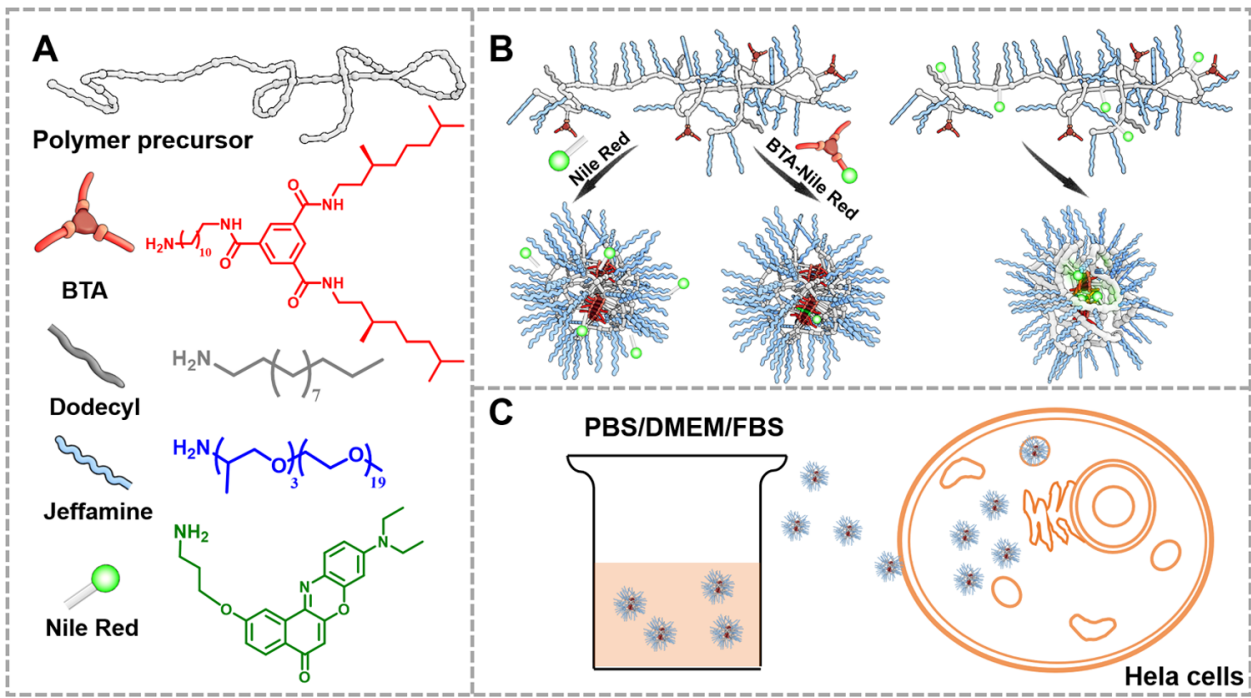

Figure 1. Schematic illustration of the incorporation of Nile red and its derivatives to amphiphilic polymers that fold into SCPNs for stability study in biological media and in living cells. (A) Chemical composition of pendant groups incorporated into amphiphilic polymers. (B) Encapsulation of Nile red or BTA-Nile red into SCPNs (left panel) and amphiphilic polymers with Nile red covalently attached folded into SCPNs (right panel). (C) Schematic representation of SCPNs in biological media and HeLa cells.

the stability of SCPNs in biological environments. Therefore, understanding the stability of SCPNs in complex media and in living cells is an essential step to facilitate their efficient biological applications. Only when these nanoparticles are able to retain their highly structured hydrophobic interior, it is possible for them to shield and protect hydrophobic molecules such as catalysts from the aqueous environment and to perform their desired functions.

Stability studies of SCPNs in biological media and in living cells are still scarce, possibly due to the difficulties of applying appropriate techniques in such complex environments. Circular dichroism (CD) spectroscopy has been reported to monitor the folding process of SCPNs with an internal helical architecture, ${ }^{44}$ but this technique is not applicable for studying the folding or unfolding of nanoparticles in biological media as biomolecules like proteins also show strong CD signals, ${ }^{45,46}$ which can interfere with the spectra of SCPNs. Dynamic light scattering (DLS) has been widely applied to study the size of particles in the presence of proteins, ${ }^{47,48}$ but this technique is not suitable for monitoring particles in living cells where it requires in situ detection. Due to the sensitive response of fluorophores to the nature of their environments and the minimal impact of these probes on designed systems, introducing fluorophores to nanoparticles and using fluorescence spectroscopy and microscopy ${ }^{49-51}$ as tools for investigating the stability of SCPNs in a cellular context is promising. Solvatochromic dyes as environment-sensitive fluorophores have been widely utilized to probe the polarity of the local environment. ${ }^{52-54}$ The intensity changes and spectral shifts of a solvatochromic dye reflect the different polarity of the dye's surroundings in the case of fluorescence. Thus, incorporating a solvatochromic dye into the hydrophobic cavity of SCPNs enables to probe the stability of SCPNs in the biological environment; if the nanoparticles are not stable and unfold into an open conformation, the local environment around the dye is more polar compared to that of the nanoparticles' folded state. Alternatively, if the nanoparticle strongly interacts with hydrophobic proteins, the dye could be present in a more apolar environment. In both cases, the maximum emission wavelength will change, reflecting an unfolding event.

In this work, we present a systematic study to elucidate the stability of SCPNs based on different amphiphilic polymers in biological media and in living cells with the aim to reveal whether these nanoparticles are able to retain a folded structure in biological environments. In our design, we use the solvatochromic dye Nile red to probe the polarity of the hydrophobic interior of SCPNs, which is indicative of a collapsed or unfolded state of SCPNs. The SCPNs studied here are designed based on our previous studies ${ }^{27}$ with a polyacrylamide-based backbone, hydrophilic Jeffamine@M1000 , to increase water solubility, hydrophobic $n$-dodecylamine, and the supramolecular moieties benzene-1,3,5tricarboxamide (BTA) to trigger the folding of polymer chains in water via hydrophobic and hydrogen-bonding interactions (Figure 1). To improve the encapsulation efficiency of Nile red, we modified Nile red by attaching a BTA molecule to interact with SCPNs through supramolecular recognition. Also, Nile red was prepared with an amine linker which can be covalently attached to amphiphilic polymers. Based on the spectral shift of Nile red mixed with nanoparticles, the polarity change of their hydrophobic interior can be followed. We first assess the stability of SCPNs in the biological relevant media phosphate-buffered saline (PBS), cell culture medium Dulbecco's modified Eagle's medium (DMEM), and DMEM with $10 \%$ fetal bovine serum (FBS) via fluorescence spectroscopy. Next, we apply different delivery strategies for SCPNs to target two compartments of HeLa cells: the cytoplasm and lysosomes. We track the intracellular localization of these SCPNs and study their stability in living cells using spectral confocal microscopy. By comparing the stability of SCPNs formed by different amphiphilic polymers in a cellular context, this study provides crucial information for the rational design of SCPNs with high stability to achieve efficient biological applications. 


\section{EXPERIMENTAL SECTION}

Materials. 3-Diethylaminophenol, 1,6-dihydroxynaphthalene, 5(diethylamino)-2-nitrosophenol, tert-butyl (3-bromopropyl)carbamate, propargyl bromide, and pentafluorophenol were purchased from Tokyo Chemical Industry (TCI) and used as received. Anhydrous triethylamine, anhydrous 1,4-dioxane, 4-cyano-4(phenylcarbonothioylthio)pentanoic acid, and lauroyl peroxide were purchased from Sigma-Aldrich and used without purification. Acryloyl chloride and $n$-dodecylamine were purchased from abcr Gute Chemie. Jeffamine@M-1000 polyetheramine was purchased from Huntsman. Azobisisobutyronitrile (AIBN) was purchased from Sigma-Aldrich and recrystallized from methanol. Dulbecco's modified Eagle's medium (DMEM) and fetal bovine serum (FBS) were purchased from Thermo Fisher Scientific. Other solvents were purchased from Biosolve except the deuterated solvents, which were purchased from Cambridge Isotopes Laboratories. 2-Hydroxy Nile red, ${ }^{55}$ Nile redalkyne, ${ }^{56}$ BTA- $\mathrm{NH}_{2}$, and BTA- $\mathrm{N}_{3}$ were prepared following literature procedures. ${ }^{27}$

Synthesis of Nile Red- $\mathrm{NH}_{2}$. To a solution of 2-hydroxy Nile red $(100 \mathrm{mg}, 0.299 \mathrm{mmol})$ in $5 \mathrm{~mL}$ of anhydrous DMF under argon, potassium carbonate $(103.3 \mathrm{mg}, 0.748 \mathrm{mmol}$ ) was added and the mixture was stirred at room temperature for $20 \mathrm{~min}$. Then, tert-butyl (3-bromopropyl)carbamate $(106.8 \mathrm{mg}, 0.449 \mathrm{mmol})$ was added, and the reaction mixture was stirred for $20 \mathrm{~h}$ at $36^{\circ} \mathrm{C}$ under argon. The mixture was washed with saline solution, and the crude compound was extracted with $\mathrm{CH}_{2} \mathrm{Cl}_{2}(3 \times 40 \mathrm{~mL})$. The $\mathrm{CH}_{2} \mathrm{Cl}_{2}$ layer was collected and dried over $\mathrm{Na}_{2} \mathrm{SO}_{4}$. Then, the solvent was removed under reduced pressure. The residual material was purified by flash column chromatography eluting with a $\mathrm{CH}_{2} \mathrm{Cl}_{2}-\mathrm{MeOH}$ gradient from 0 to $1.5 \% \mathrm{MeOH}$ to afford Nile red-Boc as a red solid $(58 \mathrm{mg}$, $40 \%)$. TFA $(0.6 \mathrm{~mL})$ was then added to a solution of Nile red-Boc (58 $\mathrm{mg}, 0.118 \mathrm{mmol})$ in $\mathrm{CH}_{2} \mathrm{Cl}_{2}(6 \mathrm{~mL})$, and the mixture was stirred at room temperature for $30 \mathrm{~min}$. The mixture was evaporated to dryness under reduced pressure and purified by flash column chromatography eluting with a mixture of $\mathrm{CH}_{2} \mathrm{Cl}_{2}-\mathrm{MeOH} 94 / 6$ to yield Nile red- $\mathrm{NH}_{2}$ as a dark red solid $(36.9 \mathrm{mg}, 80 \%) .{ }^{1} \mathrm{H}$ NMR $(400$ $\mathrm{MHz}, \mathrm{MeOD}) \delta 8.05-7.97(\mathrm{~m}, 2 \mathrm{H}), 7.53(\mathrm{~d}, J=9.2 \mathrm{~Hz}, 1 \mathrm{H}), 7.16$ $(\mathrm{dd}, J=8.8,2.6 \mathrm{~Hz}, 1 \mathrm{H}), 6.81(\mathrm{dd}, J=9.2,2.7 \mathrm{~Hz}, 1 \mathrm{H}), 6.57(\mathrm{~d}, J=$ $2.7 \mathrm{~Hz}, 1 \mathrm{H}), 6.21(\mathrm{~s}, 1 \mathrm{H}), 4.31(\mathrm{t}, J=5.7 \mathrm{~Hz}, 2 \mathrm{H}), 3.53(\mathrm{q}, J=7.1$ $\mathrm{Hz}, 4 \mathrm{H}), 3.24(\mathrm{t}, J=7.2 \mathrm{~Hz}, 2 \mathrm{H}), 2.25(\mathrm{dq}, J=13.1,6.2 \mathrm{~Hz}, 2 \mathrm{H})$, and $1.26(\mathrm{t}, J=7.1 \mathrm{~Hz}, 6 \mathrm{H})$. MALDI-TOF-MS $(\mathrm{m} / z)$ calc. for $\mathrm{C}_{23} \mathrm{H}_{25} \mathrm{~N}_{3} \mathrm{O}_{3}^{+}[\mathrm{M}]^{+}$: 391.19, found 391.25.

Synthesis of BTA-Nile Red. Nile red-alkyne $(22.3 \mathrm{mg}, 0.06$ mmol) and BTA-N ${ }_{3}(34.2 \mathrm{mg}, 0.05 \mathrm{mmol})$ were dissolved in $3 \mathrm{~mL}$ of THF under argon. Copper(II) sulfate pentahydrate $(12.5 \mathrm{mg}, 0.05$ $\mathrm{mmol})$ in water $(1 \mathrm{~mL})$ and sodium ascorbate $(19.8 \mathrm{mg}, 0.10 \mathrm{mmol})$ in water $(1 \mathrm{~mL})$ were added to the mixture under argon. The reaction was stirred at room temperature under argon for $12 \mathrm{~h}$. The copper in reaction mixture was removed by dialysis in water and the solvent was removed after dialysis under reduced pressure. The residual material was purified by chromatography with $\mathrm{CH}_{2} \mathrm{Cl}_{2}-\mathrm{MeOH} 50 / 1$ to afford BTA-Nile red as a dark red solid (44.9 mg, 85\%). ${ }^{1} \mathrm{H}$ NMR (400 $\mathrm{MHz}$, Chloroform- $d$ ) $\delta 8.39$ (dd, $J=13.1,1.6 \mathrm{~Hz}, 3 \mathrm{H}), 8.23-8.13$ (m, 2H), $7.66(\mathrm{~s}, 1 \mathrm{H}), 7.62(\mathrm{~d}, J=9.1 \mathrm{~Hz}, 1 \mathrm{H}), 7.22(\mathrm{dd}, J=8.7,2.6$ $\mathrm{Hz}, 1 \mathrm{H}), 6.80(\mathrm{t}, J=5.7 \mathrm{~Hz}, 1 \mathrm{H}), 6.72-6.58(\mathrm{~m}, 3 \mathrm{H}), 6.47(\mathrm{~d}, J=2.7$ $\mathrm{Hz}, 1 \mathrm{H}), 6.28(\mathrm{~s}, 1 \mathrm{H}), 5.43(\mathrm{~s}, 2 \mathrm{H}), 4.38(\mathrm{t}, J=7.0 \mathrm{~Hz}, 2 \mathrm{H}), 3.56-$ $3.35(\mathrm{~m}, 10 \mathrm{H}), 1.90(\mathrm{t}, J=7.3 \mathrm{~Hz}, 2 \mathrm{H}), 1.56-1.12(\mathrm{~m}, 43 \mathrm{H}), 0.91(\mathrm{~d}$, $J=6.4 \mathrm{~Hz}, 6 \mathrm{H})$, and $0.85(\mathrm{~d}, J=6.6 \mathrm{~Hz}, 12 \mathrm{H})$. MALDI-TOF-MS $(\mathrm{m} / z)$ calc. for $\mathrm{C}_{69} \mathrm{H}_{90} \mathrm{~N}_{8} \mathrm{O}_{6}^{+}[\mathrm{M}]^{+}: 1054.70$, found 1054.70 .

General Procedure for Postfunctionalization of the Prepolymer. Poly (pentafluorophenyl acrylate, DP $=200, M_{\mathrm{n}}=39 \mathrm{~kg} / \mathrm{mol}$, $Ð=1.17$ measured by SEC-THF) (100 mg, 1.0 equiv) and BTA- $\mathrm{NH}_{2}$ ( $13.7 \mathrm{mg}, 10.0$ equiv) were dissolved in a Schlenk tube in $5 \mathrm{~mL}$ of dry THF. The reaction mixture was degassed under argon for $30 \mathrm{~min}$ and stirred at $50{ }^{\circ} \mathrm{C}$ for $4 \mathrm{~h}$. Next, $n$-dodecylamine ( $11.6 \mathrm{mg}, 30$ equiv) in $2 \mathrm{~mL}$ of dry THF was added to the reaction mixture under argon and stirred for $4 \mathrm{~h}$. Finally, Jeffamine M-1000 (668 mg, 320 equiv) was added to the mixture under argon and stirred at $50{ }^{\circ} \mathrm{C}$ overnight. The polymer was purified by dialysis in THF for 2 days and then in methanol for 2 days to remove all of the pentafluorophenol and free Jeffamine. A sample was taken after each step for ${ }^{19} \mathrm{~F}$ NMR spectroscopy before adding new chemicals to the reaction mixture to monitor the conversion of each postfunctionalization step.

Nanoparticle Preparation Procedure. Polymers P2-P6 were dissolved in Milli- $Q$ water to reach a concentration of $1.5 \mu \mathrm{M}$. The mixture was vortexed and subsequently heated at $80{ }^{\circ} \mathrm{C}$ for $30 \mathrm{~min}$. The solution was then allowed to cool and was equilibrated overnight prior to measurements. For Nile red or BTA-Nile red mixed with P1, $\mathbf{P 1}$ and the appropriate amount of dye (molar ratio of polymer and dye 1:1) were first dissolved in chloroform and then the organic solvent was removed and dried in an oven under vacuum. Milli-Q water was next added to the mixture to reach a polymer concentration of $1.5 \mu \mathrm{M}$, which was followed by vortex and $10 \mathrm{~min}$ of heating at 80 ${ }^{\circ} \mathrm{C}$. The solution was then allowed to cool and was equilibrated overnight prior to measurements.

Nanoparticles Mixed with Biological Media. Polymers P2-P6 were dissolved in Milli- $\mathrm{Q}$ water to reach a stock concentration of 16.5 $\mu \mathrm{M}$. The mixture was vortexed and subsequently heated at $80^{\circ} \mathrm{C}$ for $30 \mathrm{~min}$. The solution was then allowed to cool and was equilibrated overnight. Then, $0.2 \mathrm{~mL}$ of stock solution was taken and injected into $2 \mathrm{~mL}$ of different media and equilibrated for $24 \mathrm{~h}$ before measurement. For Nile red or BTA-Nile red mixed with P1, P1 and appropriate amount of dye (molar ratio of polymer and dye 1:1) were first dissolved in chloroform and then the organic solvent was removed and dried in an oven under vacuum. Milli-Q water was next added to the mixture to reach a polymer concentration of $16.5 \mu \mathrm{M}$, which was followed by vortex and $10 \mathrm{~min}$ of heating at $80{ }^{\circ} \mathrm{C}$. The solution was then allowed to cool and was equilibrated overnight. Then, $0.2 \mathrm{~mL}$ of P1-dye stock solution was taken and injected into 2 $\mathrm{mL}$ of different media and equilibrated for $24 \mathrm{~h}$ before measurement.

Cell Viability. Hela cells culture and expansion were performed in Dulbecco's modified Eagle's medium (DMEM; Gibco) supplemented with 10\% fetal bovine serum (FBS; Gibco) and 1\% penicillin/ streptomycin (Lonza). The cytotoxicity of nanoparticles on HeLa cells was examined using the cell counting kit-8 (CCK-8) assay. HeLa cells were seeded in a 96-well plate. Each well was filled with $100 \mu \mathrm{L}$ of cell suspension containing 5000 cells. The plate was then placed in an oven at $37{ }^{\circ} \mathrm{C}$ with $5 \% \mathrm{CO}_{2}$ flow. After $24 \mathrm{~h}$, the cell culture medium was replaced with $1,1.5,2,2.5,3,3.5,4,4.5$, and $5 \mathrm{mg} \mathrm{mL}^{-1}$ of nanoparticles prepared from P2-P6 in DMEM/10\% FBS. The plate was then placed back in the oven. After $24 \mathrm{~h}$, the medium containing nanoparticles was removed and the cells were washed with PBS. One hundred microliters of DMEM and $10 \mu \mathrm{L}$ of CCK- 8 were added to each well, and the plate was placed at $37{ }^{\circ} \mathrm{C}$ for $3 \mathrm{~h}$. The absorbance of each well-containing cells was measured at $450 \mathrm{~nm}$ via a microplate reader. The values of absorbance were proportional to the number of live cells.

Delivery of Nanoparticles to Lysosomes. Cells were seeded in a $\mu$-Slide 8 well (Ibidi) plate. Each well was filled with $200 \mu \mathrm{L}$ of cell suspension containing 30000 cells. The plate was then placed in an oven at $37{ }^{\circ} \mathrm{C}$ with $5 \% \mathrm{CO}_{2}$ flow. After $24 \mathrm{~h}$, the medium was discarded. Fresh cell culture medium $(200 \mu \mathrm{L})$ containing $2 \mathrm{mg} \mathrm{mL}^{-1}$ of nanoparticles prepared by $\mathbf{P 2} \mathbf{2} \mathbf{P 6}$ was added. The plate was then placed back in the oven. After $24 \mathrm{~h}$, the medium was discarded and PBS was added to wash the cells three times.

Delivery of Nanoparticles to Cytoplasm. Cells were seeded in a $\mu$-Slide 8 well (Ibidi) plate. Each well was filled with $200 \mu \mathrm{L}$ of cell suspension containing 30000 cells. The plate was then placed in an oven at $37{ }^{\circ} \mathrm{C}$ with $5 \% \mathrm{CO}_{2}$ flow. After $48 \mathrm{~h}$, the medium was discarded and PBS was added to wash the cells three times. Four hundred microliters of PBS was then added to each well as the electroporation buffer. Electroporation was performed using a cellaxes device. A $2 \mathrm{mg} \mathrm{mL}^{-1}$ solution of nanoparticles in PBS was loaded into the tubing of the instrument, and the electrode was put in contact with the electroporation buffer. Twenty microliters of nanoparticle solution was dispensed followed by $3 \mathrm{~s}$ of electroporation using pulses at $100 \mathrm{~V}$.

Confocal Imaging. Cell nuclei and lysosomes staining were performed using Hoechst and Lysotracker green, respectively. Live 
Scheme 1. Chemical Structures of Nile Red-NH $\mathrm{H}_{2}$ and BTA-Nile Red

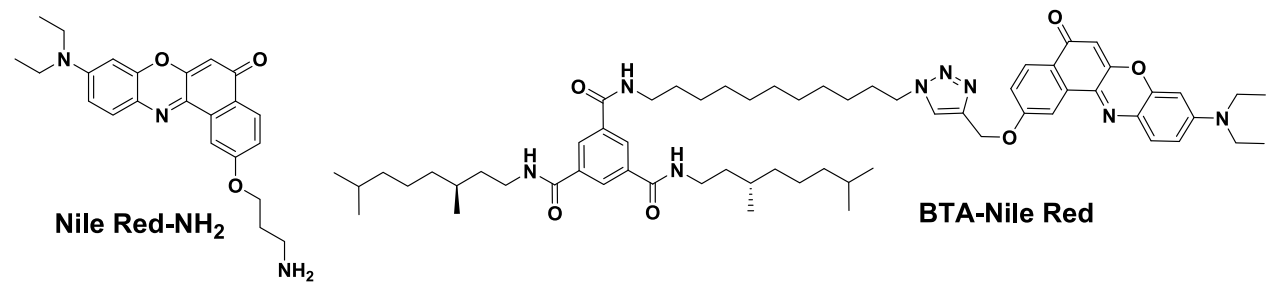

Scheme 2. Synthesis of P1-P6 by Postfunctionalization of PPFPA $_{200}$
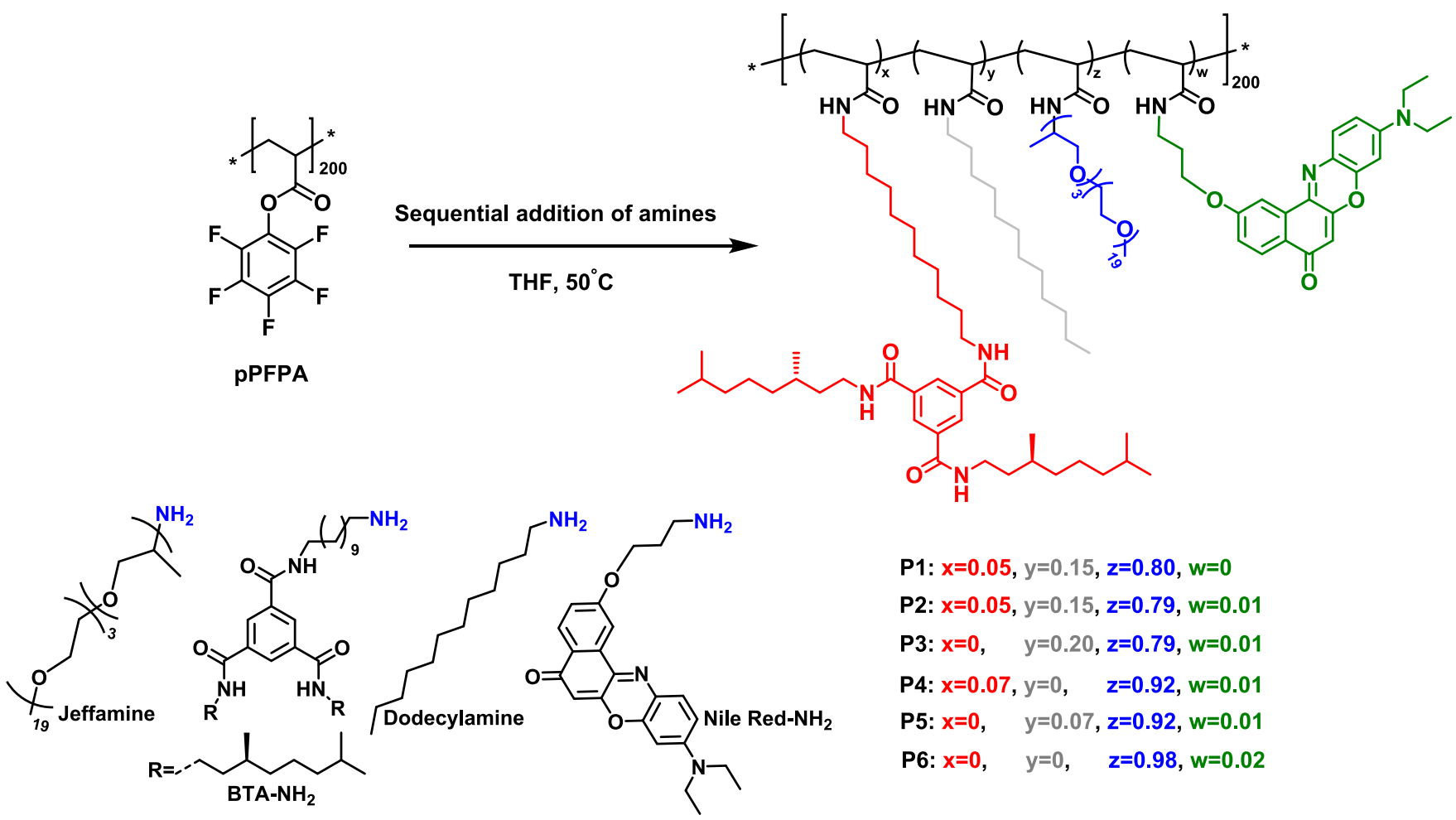

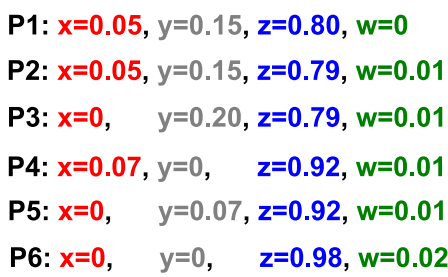

cell images were taken by a Leica TCS SP5 AOBS equipped with a $63 \times$ water immersion objective. Nile red-labeled nanoparticles (P2P6) were excited at $552 \mathrm{~nm}$, and emission was detected from 570 to $770 \mathrm{~nm}$ using the high-sensitivity $\mathrm{HyD}$ detector for the setup. The spectral image was taken by $\mathrm{xy} \lambda$ scan mode. The sequence images were plotted in Image $\mathrm{J}$ and converted into emission spectra.

\section{RESULTS AND DISCUSSION}

Synthesis of Nile Red Derivatives. We designed two Nile red derivatives, Nile red- $\mathrm{NH}_{2}$ and BTA-Nile red (Scheme 1 ), which can be covalently attached to the polymer or interact with SCPNs through supramolecular recognition, respectively. Nile red- $\mathrm{NH}_{2}$ was prepared following a modified literature procedure; details are given in the ESI. Likewise, BTA-Nile red (BTA-NR) was obtained via a Cu-catalyzed azide-alkyne cycloaddition (CuAAC) of Nile red-alkyne with an azidefunctionalized BTA; details are provided in the ESI. Both compounds were fully characterized by NMR and MALDITOF-MS (Figures S1-S5). To test whether BTA-Nile red is suitable to probe polarity changes, we dissolved BTA-Nile red in organic solvents of different polarities. As shown in Figure S6A, the maximum emission wavelength $\left(\lambda_{\text {max,em }}\right)$ of BTA-Nile red exhibits significant red shifts from 577 to $630 \mathrm{~nm}$, and its emission intensity markedly decreased with increasing the polarity of solvents, which is similar to that of Nile red in different organic solvents. As a result, the additional BTA molecule bound to Nile red does not affect its ability to sense polarity changes.

Synthesis and Characterization of Amphiphilic Polymers P1-P6. Six different amphiphilic polymers P1P6 (Scheme 2) were designed; all polymers comprise hydrophilic Jeffamine M-1000 to impart water solubility. P1 and P2 have a very similar design, 5\% supramolecular BTA motifs, and 15\% hydrophobic dodecyl groups, but P1 lacks 1\% Nile red grafted to the polymer backbone. P3 and P4 both have $1 \%$ Nile red covalently grafted but differ in the primary structure: P3 has no BTAs but 20\% dodecyl groups; P4 has no dodecyl group but 7\% BTAs. P5 has the same percentage of hydrophilic group Jeffamine as P4 but $7 \%$ dodecyl grafts instead of 7\% BTA grafts. P6 only comprises $2 \%$ Nile red and Jeffamine. With these differences in design, we expect that changes in the local polarity of SCPNs formed by P1-P6 in aqueous environments can be visualized.

Amphiphilic polymers P1-P6 were synthesized using a postfunctionalization ${ }^{57}$ procedure, which allows a singlepolymer backbone with a fixed average degree of polymerization (DP) and polydispersity $(\nexists)$ to be used for all polymer synthesis. Monomer pentafluorophenyl acrylate was first synthesized (Figures S7 and S8), and polymer precursor poly(pentafluorophenyl acrylate) $\left(\mathrm{pPFPA}_{200}, \mathrm{DP}=200, \Xi=\right.$ 
A

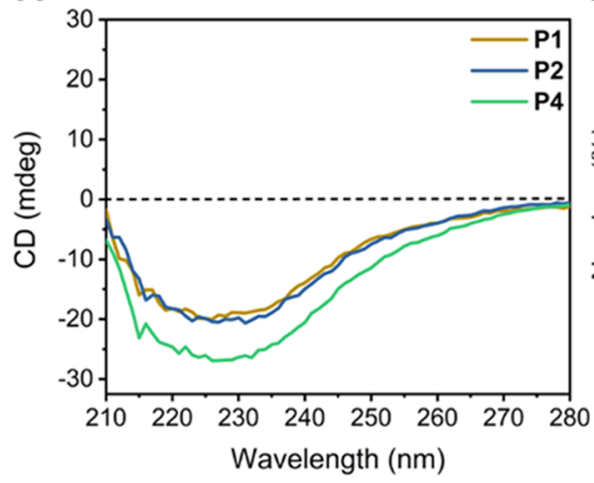

B

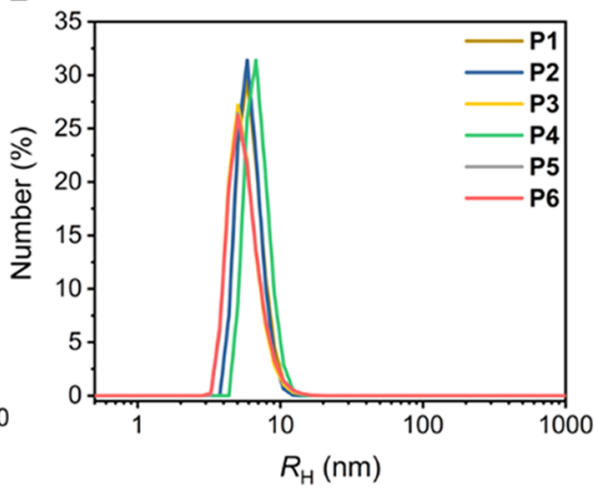

C

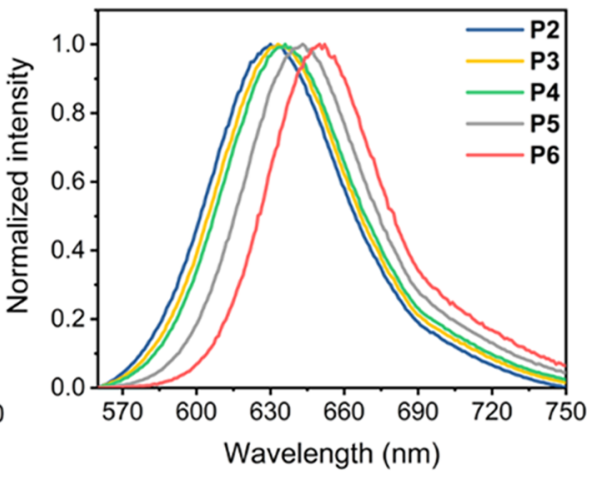

Figure 2. SCPNs formed by P1-P6 in water. (A) CD spectra of P1, P2, and P4 $\left(c_{\mathrm{P}}=1.5 \mu \mathrm{M}, T=20{ }^{\circ} \mathrm{C}\right.$, optical path length $\left.l=10 \mathrm{~mm}\right)$ in water. (B) DLS measurements of P1-P6 $\left(1 \mathrm{mg} \mathrm{mL}^{-1}, T=20^{\circ} \mathrm{C}, R_{\mathrm{H}, \mathrm{P} 1}=6.2 \mathrm{~nm}, R_{\mathrm{H}, \mathrm{P} 2}=6.1 \mathrm{~nm}, R_{\mathrm{H}, \mathrm{P} 3}=5.6 \mathrm{~nm}, R_{\mathrm{H}, \mathrm{P} 4}=6.9 \mathrm{~nm}, R_{\mathrm{H}, \mathrm{P} 5}=5.7 \mathrm{~nm}, R_{\mathrm{H}, \mathrm{P} 6}=\right.$ $5.7 \mathrm{~nm})$ in water. (C) Normalized fluorescence spectra of P2-P6 $\left(c_{\mathrm{P}}=1.5 \mu \mathrm{M}, \lambda_{\max , \mathrm{em}, \mathbf{P 2}}=630 \mathrm{~nm}, \lambda_{\max , \mathrm{em}, \mathbf{P} 3}=634 \mathrm{~nm}, \lambda_{\max , \mathrm{em}, \mathrm{P} 4}=635 \mathrm{~nm}\right.$, $\lambda_{\max , \mathrm{em}, \mathbf{P 5}}=643 \mathrm{~nm}, \lambda_{\max , \mathrm{em}, \mathbf{P 6}}=651 \mathrm{~nm}$ ) in water (see Figure S6 for original emission spectra).

1.17) was prepared via RAFT polymerization using chain transfer agent (CTA) 4-cyano-4-(phenylcarbonothioylthio)pentanoic acid and subsequent removal of the CTA end group to avoid further polymerization (Figures S9-S13). The polymer precursor $\mathrm{pPFPA}_{200}$ bearing activated ester pendants easily reacts with aliphatic amines, making the postfunctionalization process versatile. The postfunctionalization was initiated by adding amine compounds sequentially (Scheme 2 ). For the synthesis of polymer P1, the enantiomerically pure BTA- $\mathrm{NH}_{2}$ aimed at $5 \%$ incorporation was first added to the $\mathrm{pPFPA}_{200}$ solution, followed by the addition of the $n$ dodecylamine aimed at $15 \%$ incorporation. Finally, hydrophilic Jeffamine@M-1000 was introduced to complete the postfunctionalization. For the synthesis of polymers P2-P6, Nile red- $\mathrm{NH}_{2}$ ( $1 \%$ or $2 \%$ incorporation) was first added to the polymer precursor solution, and the following steps are similar to that of P1 synthesis. Due to the incorporation of amine groups, pentafluorophenol was released into the solution. ${ }^{19} \mathrm{~F}$ NMR spectroscopy can be used to monitor this process and to calculate the conversion after each amine addition step (Figure S14). The fully functionalized polymers were purified by dialysis against THF and methanol to give P1-P6 with a theoretical molecular weight of ca. $180 \mathrm{kDa}$ and molar mass dispersities of $Ð=1.15-1.22$ (measured by SEC in DMF, poly(ethyleneoxide) as standards). The results of all polymer functionalization as tracked by ${ }^{19} \mathrm{~F}$ NMR, the ${ }^{1} \mathrm{H}$ NMR spectra of purified polymers, and SEC traces are given in Figures S14S31.

Preparation of SCPNs Based on P1-P6. The randomly substituted amphiphilic polymers P1-P6 are designed to form SCPNs in water. ${ }^{27}$ The chiral BTA moieties on P1, P2, and P4 form helical aggregates of predominantly $M$ helical sense and trigger the folding of the polymer chain in water into compact conformations via threefold hydrogen-bonding interactions. This $M$ helical structure can be observed by circular dichroism (CD) spectroscopy as a negative Cotton effect with an extremum at $228 \mathrm{~nm}$. Gratifyingly, P1, P2, and P4 all exhibit a negative Cotton effect in water (Figure 2A). The CD intensities of P1 and P2, which have the same amount of BTAs incorporated, are almost identical at $228 \mathrm{~nm}$, suggesting that the incorporation of $1 \%$ Nile red to P2 does not affect the self-assembly of chiral BTA grafts. The CD intensity of P4 is higher than that of $\mathbf{P 1}$ and $\mathbf{P 2}$, which is due to a higher incorporation of BTAs (7\%) compared to P1 and P2 (5\%).
Owing to their amphiphilic properties, P3, P5, and P6 without BTA grafts also form nanoparticles in water. To determine the hydrodynamic radius $\left(R_{\mathrm{H}}\right)$ of nanoparticles formed from P1 to P6, dynamic light scattering (DLS) was applied. DLS measurements (Figure 2B) show that all amphiphilic polymers P1-P6 in water are present as nanoparticles with hydrodynamic radii $\left(R_{\mathrm{H}}\right)$ below $7.0 \mathrm{~nm}$. In particular, nanoparticles based on P3, P5, and P6 show a slightly smaller size $\left(R_{\mathrm{H}}=\right.$ 5.6-5.7 $\mathrm{nm}$ ), which is consistent with our previous studies where polymers with $20 \%$ dodecyl grafts and no BTA grafts form smaller particles. ${ }^{27}$ The values for $R_{\mathrm{H}}$ are consistent with one polymer chain folding into a single-chain polymeric nanoparticle.

We expect that the extent to which Nile red is shielded depends on the polymer's microstructure. Therefore, fluorescence spectroscopy measurements were performed on P2P6, all with Nile red covalently attached. Nile red in water is almost nonfluorescent and shows a $\lambda_{\max , \mathrm{em}}$ at $660 \mathrm{~nm}$. When the polarity of the environment decreases, $\lambda_{\max , \mathrm{em}}$ of Nile red decreases. $^{58}$ Figure $2 \mathrm{C}$ shows the normalized fluorescence spectra of P2-P6 in water. The $\lambda_{\text {max,em }}$ of P2 is $630 \mathrm{~nm}$, while P3 and P4 have a similar $\lambda_{\text {max,em }}$ at around $635 \mathrm{~nm}$. Compared to P2-P4, the $\lambda_{\text {max,em }}$ of P5 and P6 are red-shifted to 643 and $651 \mathrm{~nm}$, respectively. The differences in $\lambda_{\text {max,em }}$ indicate that the polarity around Nile red is sensitive to the polymer's microstructure. In fact, P6, with no additional hydrophobic pendants, shows a $21 \mathrm{~nm}$ higher $\lambda_{\text {max,em }}(651 \mathrm{~nm})$ than that of P2 $(630 \mathrm{~nm})$, which has a high amount of hydrophobic pendants. Thus, we conclude that Nile red is sensitive to polarity differences inside the hydrophobic pocket of SCPNs, which depends on the microstructure of P2-P6.

Unfolding of SCPNs. When SCPNs unfold, Nile red will become more exposed to the polar aqueous environment and consequently a red shift in $\lambda_{\text {max,em }}$ is expected. To better understand how the emission spectrum of Nile red changes when SCPNs adopt a more open conformation, we performed a series of experiments where we deliberately unfolded SCPNs in water. We select P4 as an example for these studies since Nile red is herein covalently attached and hydrogen bonds that assemble pendant BTAs can be disassembled, thus unfolding SCPNs. To induce unfolding, we added guanidine hydrochloride $(\mathrm{GH})$ to nanoparticles in water. $\mathrm{GH}$ is widely used as a denaturant to induce the unfolding of proteins by interrupting the secondary structure of proteins. ${ }^{59,60}$ Since 

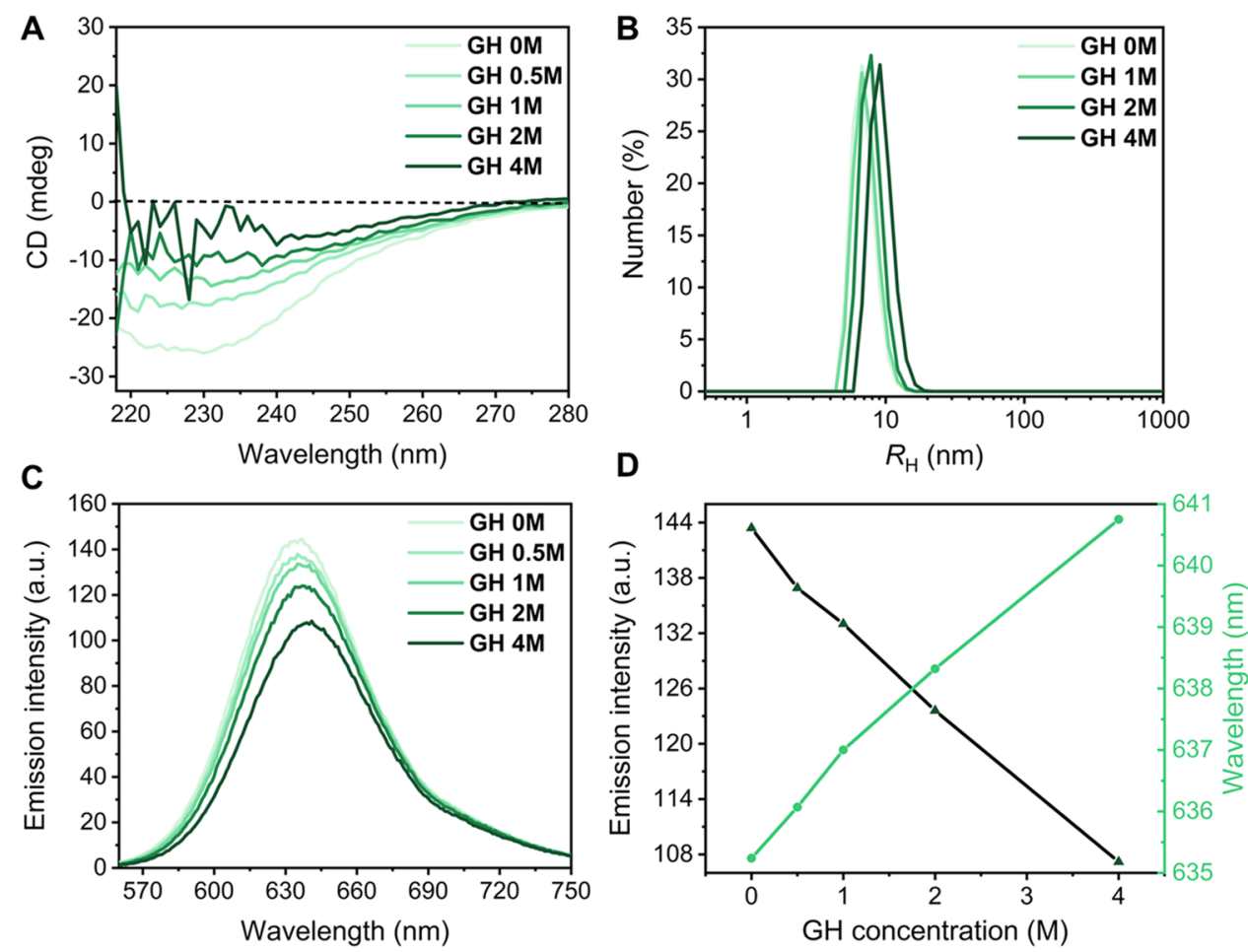

Figure 3. Unfolding of P4-based SCPNs by different concentrations of guanidine hydrochloride $(\mathrm{GH})$. (A) $\mathrm{CD}$ spectra $\left(c_{\mathrm{P}}=1.5 \mu \mathrm{M}, \mathrm{T}=20{ }^{\circ} \mathrm{C}\right.$, optical path length $l=10 \mathrm{~mm})$, (B) DLS measurements $\left(c_{\mathrm{P}}=1.5 \mu \mathrm{M}, T=20^{\circ} \mathrm{C}\right)$, (C) fluorescence spectra of $\mathbf{P 4}\left(c_{\mathrm{P}}=1.5 \mu \mathrm{M}\right)$, and $(\mathrm{D})$ change in fluorescence intensity and wavelength of $\mathbf{P 4}\left(c_{\mathrm{P}}=1.5 \mu \mathrm{M}\right)$ by increasing the concentration of $\mathrm{GH}$.
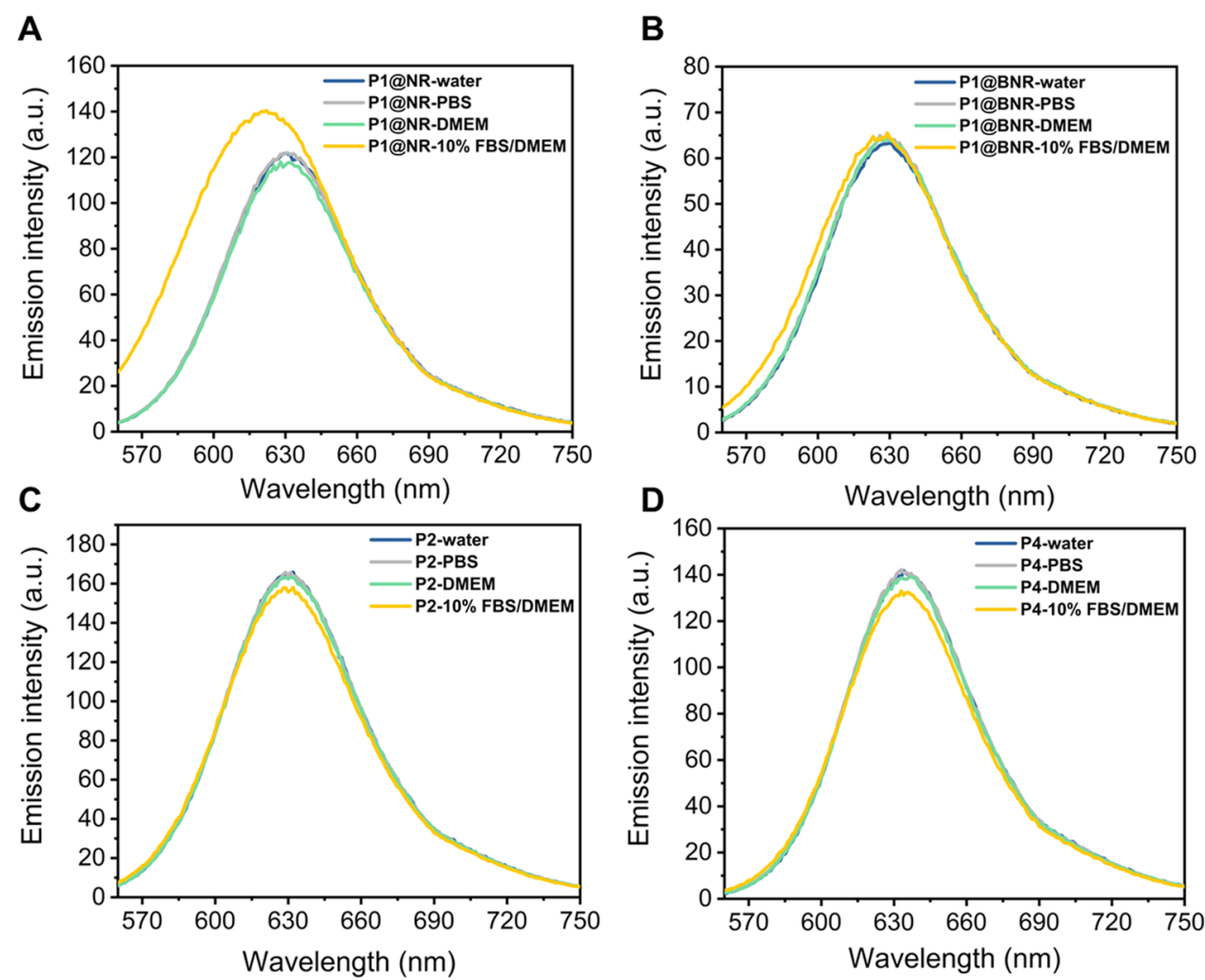

Figure 4. SCPNs in different biological media. Fluorescence spectra of (A) P1@NR $\left(c_{\text {Nile red }}=1.5 \mu \mathrm{M}, c_{\mathrm{P} 1}=1.5 \mu \mathrm{M}\right)$, (B) P1@BTA-NR $\left(c_{\mathrm{BTA} \text {-Nile red }}=1.5 \mu \mathrm{M}, c_{\mathrm{P} 1}=1.5 \mu \mathrm{M}\right)$, (C) P2 $\left(c_{\mathrm{P} 2}=1.5 \mu \mathrm{M}\right)$, and (D) P4 $\left(c_{\mathrm{P} 4}=1.5 \mu \mathrm{M}\right)$ in water, PBS, DMEM, and DMEM with $10 \%$ FBS.

BTA units drive the folding of the polymer via hydrogen-bond interactions, $\mathrm{GH}$ is expected to break the hydrogen-bond interaction between BTA molecules and partially unfold
SCPNs. Figure 3A shows that the CD effect of P4 decreases gradually upon increasing the concentration of $\mathrm{GH}$, indicating the disassembly of chiral BTA molecules in P4. Although the 
A

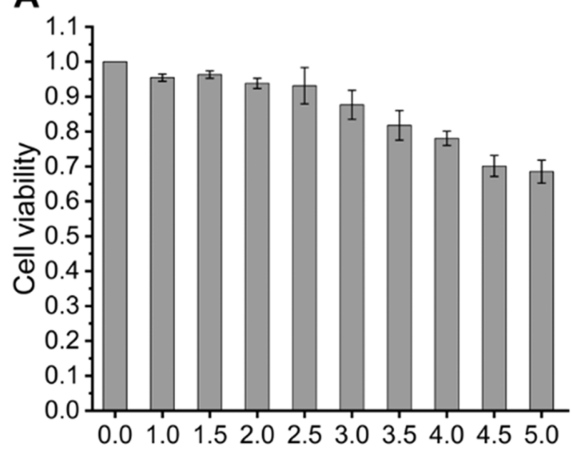

D

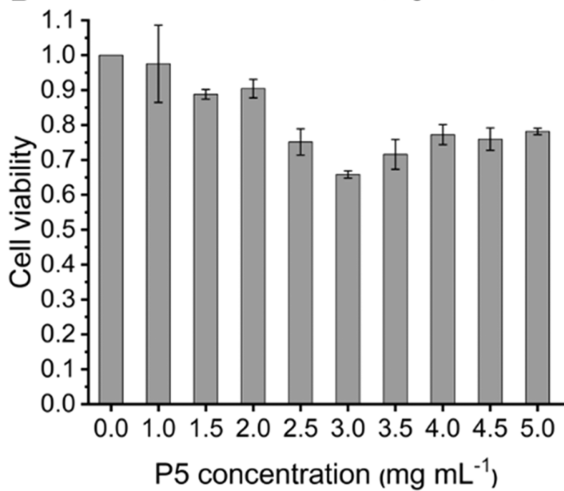

B

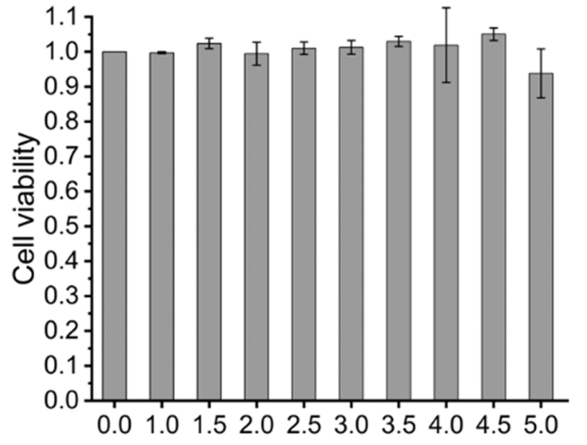

E

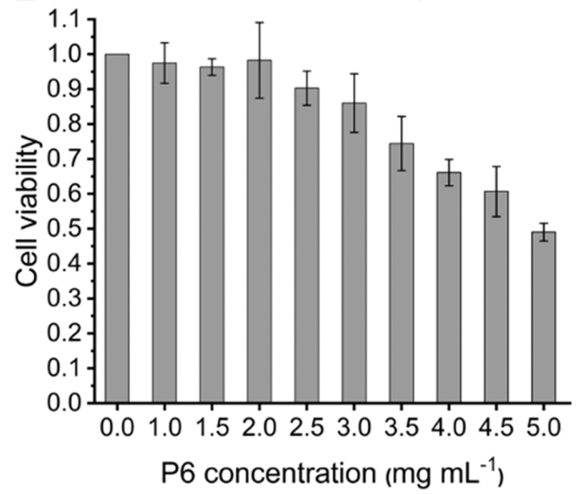

C

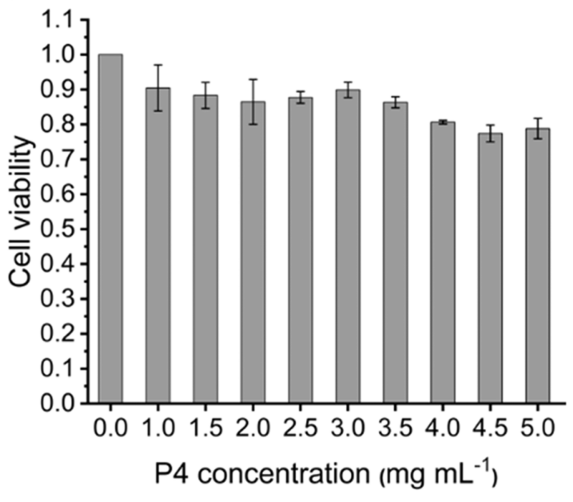

Figure 5. Cytotoxicity of P2-P6 in HeLa cells determined by CCK-8 assay. Different concentrations of SCPNs formed by (A) P2, (B) P3, (C) P4, (D) P5, and (E) P6 are incubated with HeLa cells for $24 \mathrm{~h}$.

increase in $\mathrm{GH}$ concentrations causes an increase in absorbance, a detailed analysis of $\mathrm{CD}$ traces showed that reliable CD signals were obtained when the concentration of $\mathrm{GH}$ was equal to or below $2 \mathrm{M}$ (see Figure S32 for details).

A more unfolded particle is expected to result in an increase in the hydrodynamic radius $\left(R_{\mathrm{H}}\right)$ of the particle as a more random coil conformation can be adopted or additional hydrophobic aggregation occurs to limit exposure of the hydrophobic moieties to the aqueous environment. To assess this, we studied the size change of $\mathbf{P 4}$ upon adding GH by DLS (Figure $3 \mathrm{~B}$ ). Increasing the concentration of $\mathrm{GH}$ results in a gradual increase of $R_{\mathrm{H}}$ from 7.0 to $9.4 \mathrm{~nm}$. In addition, the fluorescence spectra (Figure 3C) of P4 show that the emission intensity gradually decreases with increasing the concentration of $\mathrm{GH}$. At the same time, the $\lambda_{\text {max,em }}$ of the nanoparticles shows a red shift from 635 to $641 \mathrm{~nm}$. Interestingly, adding $\mathrm{GH}$ to pure Nile red- $\mathrm{NH}_{2}$ in water as a control results in a significant increase of the emission intensity (Figure S33), while the maximum emission wavelength of Nile red- $\mathrm{NH}_{2}$ in water and $\mathrm{GH}$ is almost identical. This suggests that the change in the fluorescence signal of $\mathbf{P 4}$ in the presence of $\mathrm{GH}$ is mainly due to the unfolding of nanoparticles instead of the dye's interaction with $\mathrm{GH}$. These observations corroborate that Nile red covalently attached to P4 experiences a more polar local environment when $\mathrm{GH}$ is added.

All results combined - a reduction in the $\mathrm{CD}$ effect, a size increase as observed by DLS, and a decrease in emission intensity with concomitant red shift-indicate that the (partial) unfolding of SCPNs exposes Nile red to more water, and consequently, Nile red responds to the local environment by changing its fluorescence signal. We infer from these results that $\lambda_{\text {max,em }}$ of Nile red is a suitable tool to reflect the stability of SCPNs.
Stability of SCPNs in Complex Media. To study the stability of SCPNs formed by P1-P6 in media of increasing complexity, we selected the following biologically relevant media: PBS buffer, cell culture medium DMEM, and DMEM supplemented with $10 \%$ fetal bovine serum (FBS). As a reference, we physically mixed Nile red with P1, which does not have a dye covalently attached. We also introduced BTANile red into P1 via supramolecular recognition. The effective encapsulation of Nile red or BTA-Nile red by P1 can be seen in absorbance spectra, CD spectra, and DLS measurements (Figures S34 and S35).

Figure 4A-D shows the emission spectra of SCPNs for P1@ NR, P1@BTA-NR, P2, and P4, respectively, all measured in water, PBS, DMEM, and DMEM with $10 \%$ FBS. The emission spectra of P3, P5, and P6 in different media are shown in Figure S36. In all cases, the spectra of SCPNs in PBS buffer and DMEM are quite similar to their counterparts in water, suggesting that PBS and DMEM have little influence on the stability of these nanoparticles. DLS data and CD results also confirm that the size of nanoparticles and self-assembly properties of chiral BTA molecules within nanoparticles in PBS and DMEM do not change (Figures S37-S43). Specifically, for $\mathbf{P 2}$ and $\mathbf{P 4}$, where Nile red is covalently attached, the fluorescence intensity change in PBS and DMEM is negligible. However, in the presence of $10 \% \mathrm{FBS}$, the fluorescence spectra of P2 and P1@NR differ. For P1@NR, the emission intensity increases significantly and the $\lambda_{\text {max,em }}$ blue shifts from 630 to $620 \mathrm{~nm}$. In contrast, for P2, the emission intensity shows only a slight decrease and the $\lambda_{\text {max,em }}$ remains constant in the presence of FBS. P1 and P2 have a very similar chemical structure; the only difference is that P2 has an additional $1 \%$ Nile red covalently attached. 
Nuclei

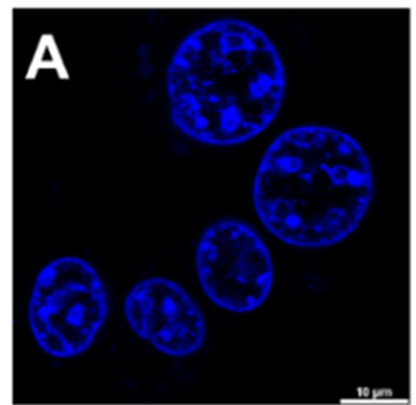

B
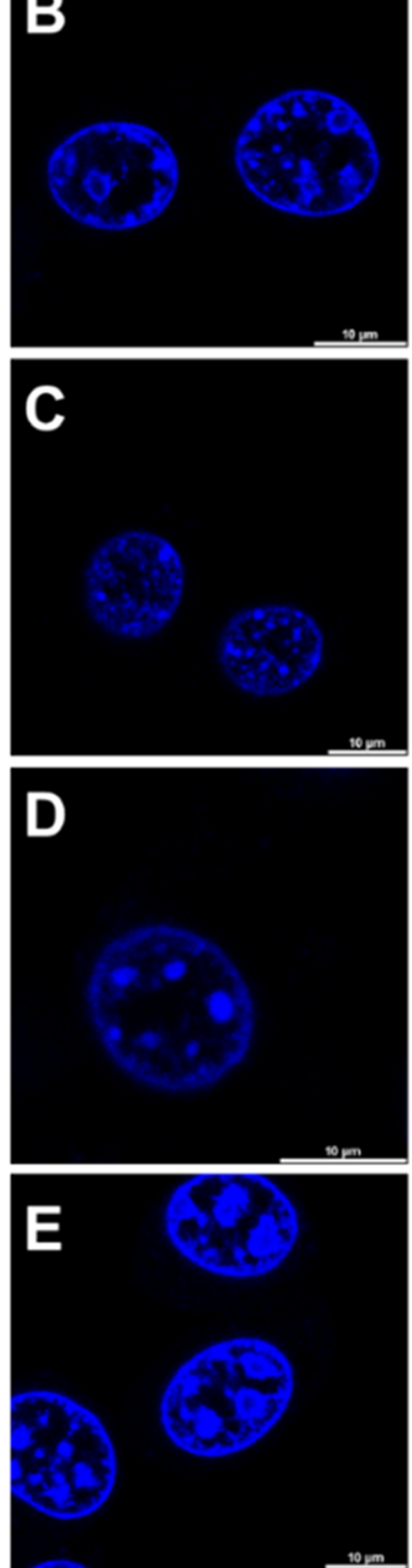

SCPNs
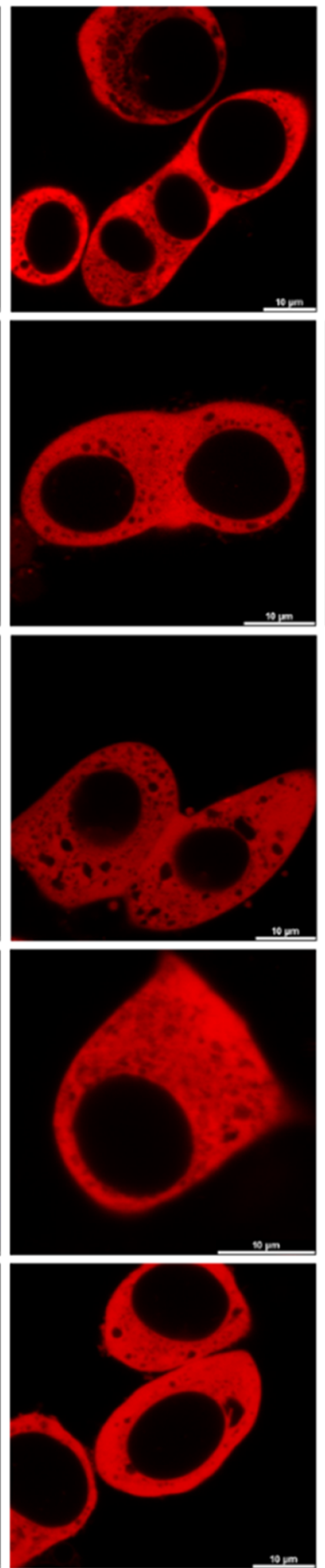

Merge
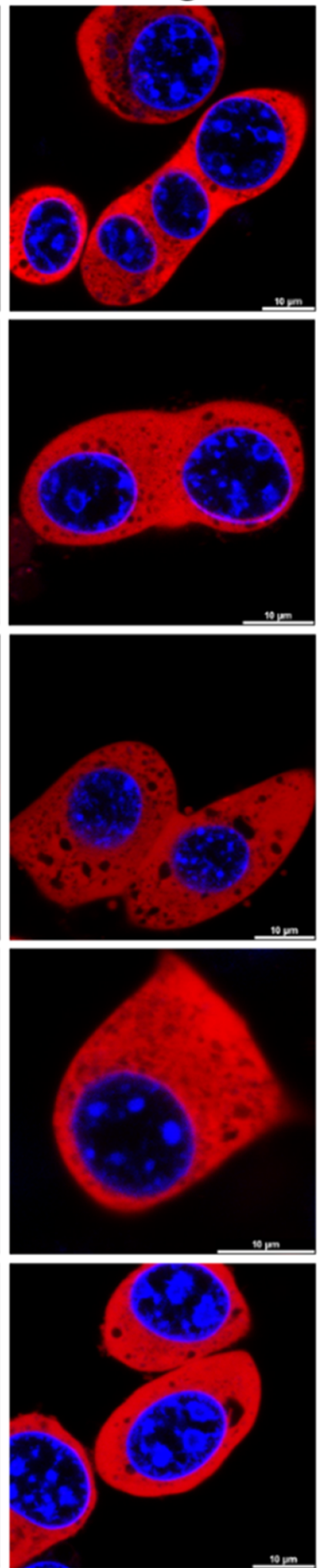

\section{Emission spectra}
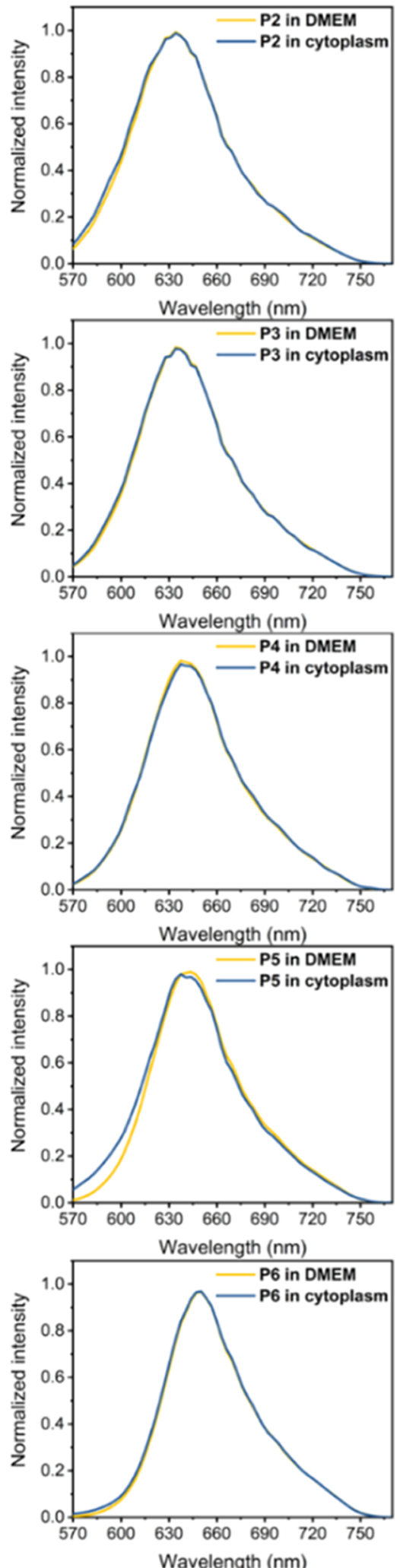

Figure 6. Delivery of SCPNs to the cytoplasm of HeLa cells for the stability study. Confocal microscopy images and emission spectra of SCPNs based on (A) P2, (B) P3, (C) P4, (D) P5, and (E) P6 in cytoplasm after electroporation. The emission spectra of SCPNs outside cells in DMEM were also taken as a reference. The blue and red colors indicate cell nuclei stained with Hoechst and cytoplasm stained with SCPNs formed by P2P6, respectively. 
We assume that the different results between P1@NR and P2 in the presence of 10\% FBS are due to the leakage of Nile red from P1. To corroborate this, we studied the interaction between Nile red and FBS. As shown in Figure S44, the UVvis measurement shows a maximum absorbance of Nile red in FBS at $560 \mathrm{~nm}$, which suggests that Nile red can partially dissolve in FBS. The fluorescence measurement shows that Nile red in FBS emits strongly, with $\lambda_{\text {max,em }}$ at around $620 \mathrm{~nm}$, which is similar to the emission spectrum of P1@NR in the presence of $10 \%$ FBS. These observations corroborate that Nile red leaks out from $\mathbf{P 1}$ and interacts with the hydrophobic patches of the proteins contained in FBS, which provide a more hydrophobic environment for Nile red to localize in. In addition, the emission spectra of P1@BTA-NR only show a slight signal broadening in DMEM with 10\% FBS compared to that of P1@NR. This suggests that the supramolecular recognition between BTA-Nile red and P1 makes it difficult for the dye to escape from nanoparticles.

A decrease of emission intensity between P2 and P4 in the presence of FBS was also observed. To explain this emission intensity change, we measured the absorbance spectrum of FBS. As shown in Figure S45A, there are some absorption peaks above $580 \mathrm{~nm}$, which overlap with the emission peaks of P2 and P4. The absorption peaks in FBS belong to hemoglobin, which was reported to reduce the emission intensity of a dye whose fluorescence spectrum overlaps with the absorbance spectrum of hemoglobin. ${ }^{61}$ This means that in the presence of FBS, the emitted light from Nile red may be absorbed by hemoglobin in FBS. To verify this, we mixed nanoparticles prepared by $\mathbf{P 2}$ and hemoglobin and found that in the presence of hemoglobin, the emission intensity of SCPNs decreased (Figure S46). Although the emission intensity of P2 and P4 decreased in the presence of FBS, the $\lambda_{\text {max,em }}$ of these SCPNs hardly changed and remained around 630 and $635 \mathrm{~nm}$, respectively. This suggests that the local polarity around Nile red does not significantly change. This observation indicates that SCPNs are still in a folded structure in the presence of FBS. Overall our results indicate that SCPNs are generally stable in biological media, with the polymers P2P6 giving the most promising results. Although the supramolecular recognition between BTA-Nile red and P1 makes it difficult for the dye to escape from nanoparticles, when it comes to a cellular environment, there may be more chance of leakage of BTA-Nile red compared to the Nile red covalently attached to polymer system. We therefore continue our studies in living cells with P2-P6 in which Nile red is covalently attached.

Cytotoxicity of SCPNs on HeLa Cells. Before analyzing the behavior of P2-P6-based SCPNs in cells, we first studied their cytotoxicity properties and selected HeLa cells as they are commonly used human cell lines for studying biological applications of nanoparticles. HeLa cells were incubated with SCPNs at concentrations ranging from 1 to $5 \mathrm{mg} / \mathrm{mL}$, and the cell viability was tested using the CCK- 8 assay. We focus here on SCPNs formed by P2-P6 because these polymers have Nile red covalently attached, which can be used for visualizing and collecting emission spectra in living cells. With CCK-8 reagent, the absorbance of formazan produced by living cells at $450 \mathrm{~nm}$ was detected for viability calculation. Figure 5A,C shows that up to $3.5 \mathrm{mg} / \mathrm{mL}$ of $\mathbf{P 2}$ and $\mathbf{P 4}$, more than $80 \%$ of $\mathrm{HeLa}$ cells remained viable. Cell viability showed a slight decrease to $70 \%$ when increasing the concentration to $5 \mathrm{mg}$ / $\mathrm{mL}$. Figure 5D,E shows that cell viability remained above $80 \%$ when the concentration of SCPNs increased to $2 \mathrm{mg} / \mathrm{mL}$ for P5 and $3 \mathrm{mg} / \mathrm{mL}$ for P6. Interestingly, Figure 5B shows that increasing the concentration of nanoparticles formed by $\mathbf{P} 3$ did not affect cell viability. Up to $5 \mathrm{mg} / \mathrm{mL}$, more than $90 \%$ of cells remained viable. The surprising differences between the effect of different polymer microstructures on cell viability is currently not well understood. An explanation may be found in the shape of the nanoparticles that differ for SCPNs prepared by the different polymers. For example, previous research showed that the presence of only BTA pendants, as in P4, affords elongated SCPNs, ${ }^{62}$ whereas SCPNs with $20 \%$ dodecyl grafts, like in P3, may adopt a more spherical shape. Nanoparticles with no or only few hydrophobic pendants adopt a more open, random coil conformation, like in P5 and P6. There seems to be a correlation between the SCPNs that are conformationally less restricted (P5 and P6) and a slightly increased cytotoxicity to HeLa cells at higher SCPN concentration. This may be due to the ability of nonrestricted SCNPs to expose hydrophobic parts to the cell, inducing membrane damage.

Stability of SCPNs Inside Cells. We targeted two compartments inside HeLa cells to evaluate SCPN stability, namely, the cytoplasm and lysosomal organelles. These have been chosen for their relevance in the drug/catalyst delivery process. The cellular cytoplasm provides a highly crowded environment of neutral $\mathrm{pH}$ but with a high content of ions and biological macromolecules. In contrast, the lysosomal organelles have a low $\mathrm{pH}$ of $4.5-5$ and provide a highly hostile environment due to the high content of hydrolytic enzymes capable of degrading proteins, nucleic acids, lipids, and carbohydrates.

To transport SCPNs to the two compartments, different delivery methods are required. Nanoparticles were reported to reach the lysosomal organelles of cells via endocytosis, ${ }^{63}$ while the delivery of SCPNs to cytoplasm relies on electroporation. ${ }^{64}$ In electroporation, a pulsed electric field is applied to the medium containing target cells, resulting in the formation of aqueous pores in the cell membrane, caused by the reorientation of the lipids. This technique allows a variety of cargos ranging from small synthesized nanoparticles to larger proteins/antibodies to cross the membrane and easily access the cytoplasm of the cells. ${ }^{65}$ Here, we applied an electric voltage at $100 \mathrm{~V}$ to HeLa cells while loading different nanoparticle solutions based on P2-P6 to the cells. Figure 6 shows that SCPNs are distributed evenly inside the cytoplasm after electroporation. It is also clear that the SCPNs are excluded from the nucleus, which is not surprising as the size of SCPNs exceeds that of the nuclear pore. More images of SCPNs in the cytoplasm of cells can be found in Figure S47.

After successful delivery of SCPNs to cytoplasm, the stability of SCPNs based on P2-P6 was further studied by their emission spectra detected via confocal microscopy. The excitation wavelength of SCPNs was set as $552 \mathrm{~nm}$, and the fluorescence emission range was collected starting from 570 up to $770 \mathrm{~nm}$. Figure 6 shows the emission spectra of SCPNs in cytoplasm and in cell culture medium DMEM using the same detection setting. In the cytoplasm, the emission spectra of SCPNs based on P2, P3, P4, and P6 are very similar to those in DMEM, suggesting that SCPNs retain their folded structures. However, we see a slight emission spectrum broadening (Figure 6D) for P5. The broadening of the emission signal in the cytoplasm may be caused by the binding of various proteins to P5-based SCPNs. It is noteworthy that 


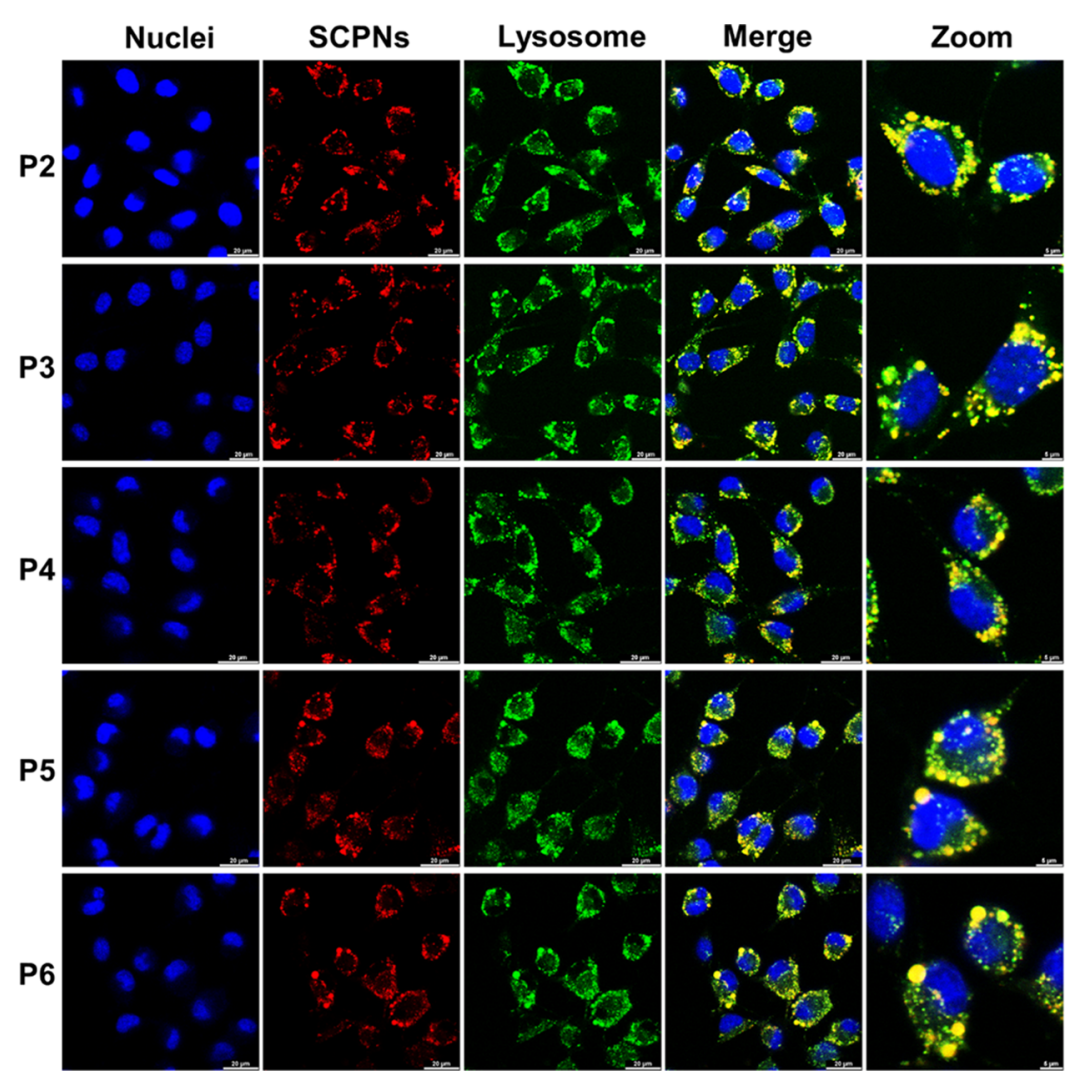

Figure 7. Delivery of SCPNs to the lysosomes of HeLa cells for the stability study. The confocal images of SCPNs based on P2-P6 in the lysosomes of HeLa cells. The blue, red, and green colors indicate cell nuclei stained with Hoechst, SCPNs, and lysosomes stained with LysoTracker Green, respectively.
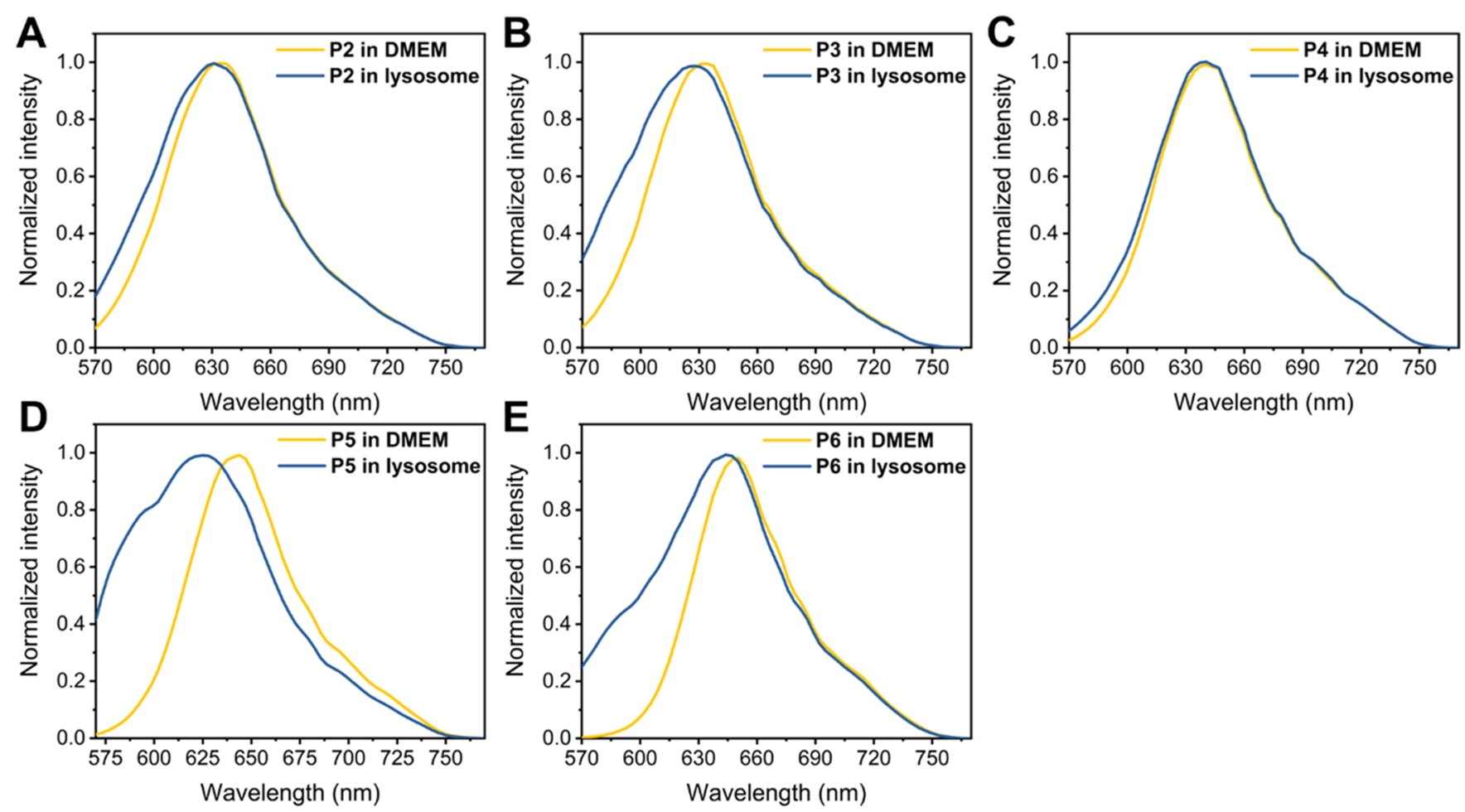

Figure 8. Emission spectra of SCPNs based on (A) P2, (B) P3, (C) P4, (D) P5, and (E) P6 outside cells in DMEM and in the lysosomes of HeLa cells as measured by confocal microscopy.

SCPNs possess an inherent heterogeneity as a result of the polymer's molar mass dispersity and the random incorporation of different grafts. Consequently, some particles interact with proteins and may not be able to shield Nile red well from 
protein binding, while some particles may be able to retain their hydrophobic interior. The broadening of the signal suggests that SCPNs formed by P5 may interact with proteins more significantly compared to other SCPNs. We also tested the effect of different electroporation voltages on the folding behavior of SCPNs in cytoplasm (Figure S48). The results show that the stability of SCPNs in cytoplasm is not affected by the applied voltage.

As the stability of SCPNs in the cytoplasm proved to be quite high, we further investigated whether these nanoparticles were able to retain their folded structures in the lysosomal organelles. Thus, we delivered SCPNs formed by P2-P6 to lysosomes via an endocytic route. Based on the cytotoxicity experiments, a high concentration of $2 \mathrm{mg} \mathrm{mL}^{-1}$ of polymers was administered to incubate HeLa cells with SCPNs. After 24 $h$, the accumulation of SCPNs in HeLa cells with a characteristic vesicular localization was observed. The slow internalization was also reported for PEGylated particles of similar size possibly due to Jeffamine@M-1000 as part of polymer pendant groups reducing interactions between nanoparticles and cells. ${ }^{31,66}$ To confirm the lysosomal localization of SCPNs based on P2-P6 inside HeLa cells, a colocalization assay with lysotracker was applied. From confocal microscopy images (Figure 7), we observe that the red signal from nanoparticles and the green signal from lysosomes overlap well, which suggests a high degree of localization of SCPNs in the lysosomes.

Next, we investigated the stability of SCPNs based on P2P6 in the lysosomes of HeLa cells. Figure 8A-E shows the emission spectra of SCPNs in lysosomes and in cell culture medium DMEM using the same detection setting. A broadening of emission spectra and a slight blue shift for SCPNs based on P2 and P3 (Figure 8A,B) were observed in lysosomes compared to those in DMEM. A comparison of emission spectra between P2 (1\% Nile red, 5\% BTA, 15\% dodecyl, and 79\% Jeffamine) and P3 (1\% Nile red, 20\% dodecyl, and $79 \%$ Jeffamine) shows that the replacement of $5 \%$ dodecyl with BTAs decreases the signal broadening and blue shift, which suggests that introducing supramolecular BTA motif is likely to stabilize the hydrophobic interior of SCPNs and protect Nile red from the outer environment. In contrast, compared to P3, which contains 20\% dodecyl, SCPNs formed by P5 with a percentage of dodecyl of only $7 \%$ show an obvious blue shift and signal broadening of the emission spectrum in lysosomes compared to those in DMEM (Figure 8D). The broadening and blue shift indicate that the Nile red in SCPNs formed by P5 experiences a less polar environment, possibly due to the open conformation of nanoparticles and interaction of Nile red with proteins inside the lysosomes. Compared to P5, P4 with 7\% BTA grafts shows remarkably different emission spectra. Only a minor broadening of the fluorescence signal of $\mathbf{P 4}$ in lysosomes (Figure 8C) compared to that in DMEM is observed, suggesting that these nanoparticles are relatively stable. When comparing all emission spectra based on P2-P6, it seems that SCPNs formed by $\mathbf{P 4}$ are the most stable ones. This may be due to a combination effect of increasing the percentage of hydrophilic group Jeffamine and supramolecular motif BTA. Jeffamine was reported to prevent protein binding, ${ }^{66}$ while the hydrogenbond interaction between BTA molecules may stabilize the conformation of nanoparticles, which contributes to the stability of these SCPNs in lysosomes. Interestingly, P6, where only Jeffamine grafts are present, shows a decrease in the blue shift and signal broadening compared to that of P5 in lysosomes (Figure 8E). Possibly, the increased Jeffamine in P6 may further decrease the protein binding and thus reduce the approaching of proteins to Nile red embedded in the polymer. Furthermore, we performed the stability study of SCPNs formed by $\mathbf{P 4}$ and P5 in cell lines that are not derived from metabolically active cancer cells. We selected HUVEC cells as a representative for primary cells and NIN3T3 cells as a representative for noncancer cells (Figure S49). The results are consistent with what was observed in HeLa cells: SCPNs formed by $\mathbf{P 4}$ show high stability, while SCPNs formed by P5 are significantly less stable in the lysosomes of cells.

\section{CONCLUSIONS}

In this work, a systematic study toward the stability of SCPNs was performed in complex biological media and in living cells using a solvatochromic dye Nile red as the probe. Amphiphilic polymers comprising different percentages of grafts consisting of hydrophilic Jeffamine, hydrophobic dodecyl and/or BTA, and fluorescent dye Nile red were prepared via a postfunctionalization approach. These polymers form water-soluble SCPNs with $R_{\mathrm{H}}$ between 5.6 and $7.0 \mathrm{~nm}$, with a hydrophobic interior as evidenced by the emission spectra of Nile red. Stability studies show that SCPNs prepared by amphiphilic polymers with different microstructures are stable in PBS, DMEM, and DMEM supplemented with 10\% FBS. In addition, the SCPNs comprising Nile red show good biocompatibility toward HeLa cells. SCPNs were also successfully delivered to the cytoplasm and lysosomes of HeLa cells. Spectral confocal microscopy reveals that these nanoparticles mostly retain their folded structures and are stable in the cytoplasm. In lysosomes, in contrast, only those SCPNs comprising BTAs show sufficient stability, likely a result of the additional hydrogen-bond interactions between BTA molecules that stabilize the interior of the nanoparticles and thus shield Nile red from the hostile environment. The detailed stability study of SCPNs in biologically relevant media and in cellular environments improves our understanding of the rational design of SCPN-based systems, paving the way for the utilization of stable SCPNs for desired biological applications with high efficiency.

\section{ASSOCIATED CONTENT}

\section{(s) Supporting Information}

The Supporting Information is available free of charge at https://pubs.acs.org/doi/10.1021/acs.biomac.1c01291.

Synthesis procedures of Nile red- $\mathrm{NH}_{2}$, BTA-Nile red, and polymers P1-P6; Characterization of modified Nile red and P1-P6 via ${ }^{1} \mathrm{H}$ NMR, MALDI-TOF-MS, ${ }^{19} \mathrm{~F}$ NMR, and SEC; Spectroscopic and light-scattering characterization of SCPNs in biological media; and Confocal images and emission spectra of SCPNs in living cells (PDF)

\section{AUTHOR INFORMATION}

\section{Corresponding Author}

Anja R. A. Palmans - Laboratory for Macromolecular and Organic Chemistry, Department of Chemical Engineering and Chemistry and Institute for Complex Molecular Systems, Eindhoven University of Technology, 5600 MB Eindhoven, The Netherlands; (1) orcid.org/0000-0002-7201-1548; Email: a.palmans@tue.nl 


\section{Authors}

Linlin Deng - Laboratory for Macromolecular and Organic

Chemistry, Department of Chemical Engineering and Chemistry and Institute for Complex Molecular Systems, Eindhoven University of Technology, 5600 MB Eindhoven, The Netherlands

Lorenzo Albertazzi - Molecular Biosensing for Medical Diagnostics, Department of Biomedical Engineering and Institute for Complex Molecular Systems, Eindhoven University of Technology, $5600 \mathrm{MB}$ Eindhoven, The Netherlands; (1) orcid.org/0000-0002-6837-0812

Complete contact information is available at: https://pubs.acs.org/10.1021/acs.biomac.1c01291

\section{Notes}

The authors declare no competing financial interest.

\section{ACKNOWLEDGMENTS}

This work is financed by the European Union's Horizon 2020 research and innovation program under the Marie SklodowskaCurie Grant Agreement no. 765497 (THERACAT). The ICMS animation studio is acknowledged for providing the artwork. Dr. Gijs ter Huurne is acknowledged for providing BTA- $\mathrm{N}_{3}$ and BTA- $\mathrm{NH}_{2}$. Dr. Joppe Oldenburg is acknowledged for providing HUVEC cells.

\section{REFERENCES}

(1) Harth, E.; Van Horn, B.; Lee, V. Y.; Germack, D. S.; Miller, R. D.; Hawker, C. J. A Facile Approach to Architecturally Defined Nanoparticles VTA Intramolecular Chain Collapse and Living Free Radical Procedures. J. Am. Chem. Soc. 2002, 43, 106-107.

(2) Ouchi, M.; Badi, N.; Lutz, J. F.; Sawamoto, M. Single-Chain Technology Using Discrete Synthetic Macromolecules. Nat. Chem. 2011, 3, 917-924.

(3) Altintas, O.; Barner-Kowollik, C. Single Chain Folding of Synthetic Polymers by Covalent and Non-Covalent Interactions: Current Status and Future Perspectives. Macromol. Rapid Commun. 2012, 33, 958-971.

(4) Pomposo, J. A. Bioinspired Single-Chain Polymer Nanoparticles. Polym. Int. 2014, 63, 589-592.

(5) Gonzalez-Burgos, M.; Latorre-Sanchez, A.; Pomposo, J. A. Advances in Single Chain Technology. Chem. Soc. Rev. 2015, 44, 6122-6142.

(6) Hanlon, A. M.; Lyon, C. K.; Berda, E. B. What Is Next in SingleChain Nanoparticles? Macromolecules 2016, 49, 2-14.

(7) ter Huurne, G. M.; Palmans, A. R. A.; Meijer, E. W. Supramolecular Single-Chain Polymeric Nanoparticles. CCS Chem. 2019, 1, 64-82.

(8) De Luzuriaga, A. R.; Ormategui, N.; Grande, H. J.; Odriozola, I.; Pomposo, J. A.; Loinaz, I. Intramolecular Click Cycloaddition: An Efficient Room-Temperature Route towards Bioconjugable Polymeric Nanoparticles. Macromol. Rapid Commun. 2008, 29, 1156-1160.

(9) Sanchez-Sanchez, A.; Pérez-Baena, I.; Pomposo, J. A. Advances in Click Chemistry for Single-Chain Nanoparticle Construction. Molecules 2013, 18, 3339-3355.

(10) Berkovich, I.; Mavila, S.; Iliashevsky, O.; Kozuch, S.; Lemcoff, N. G. Single-Chain Polybutadiene Organometallic Nanoparticles: An Experimental and Theoretical Study. Chem. Sci. 2016, 7, 1773-1778. (11) ter Huurne, G. M.; Voets, I. K.; Palmans, A. R. A.; Meijer, E. W. Effect of Intra- versus Intermolecular Cross-Linking on the Supramolecular Folding of a Polymer Chain. Macromolecules 2018, 51, $8853-8861$.

(12) Kobernik, V.; Phatake, R. S.; Tzadikov, J.; Reany, O.; Lemcoff, N. G. Organometallic Single-Chain Polymer Nanoparticles via IntraChain Cross-Linking with Dinuclear $\mu$-Halo(Diene)Rh(I) Complexes. React. Funct. Polym. 2021, 165, No. 104971.
(13) Benito, A. B.; Aiertza, M. K.; Marradi, M.; Gil-Iceta, L.; Shekhter Zahavi, T.; Szczupak, B.; Jiménez-González, M.; Reese, T.; Scanziani, E.; Passoni, L.; Matteoli, M.; De Maglie, M.; Orenstein, A.; Oron-Herman, M.; Kostenich, G.; Buzhansky, L.; Gazit, E.; Grande, H. J.; Gómez-Vallejo, V.; Llop, J.; Loinaz, I. Functional Single-Chain Polymer Nanoparticles: Targeting and Imaging Pancreatic Tumors in Vivo. Biomacromolecules 2016, 17, 3213-3221.

(14) Bai, Y.; Feng, X.; Xing, H.; Xu, Y.; Kim, B. K.; Baig, N.; Zhou, T.; Gewirth, A. A.; Lu, Y.; Oldfield, E.; Zimmerman, S. C. A Highly Efficient Single-Chain Metal-Organic Nanoparticle Catalyst for Alkyne-Azide "Click" Reactions in Water and in Cells. J. Am. Chem. Soc. 2016, 138, 11077-11080.

(15) Kröger, A. P. P.; Paulusse, J. M. J. Single-Chain Polymer Nanoparticles in Controlled Drug Delivery and Targeted Imaging. J. Control. Release 2018, 286, 326-347.

(16) Morishima, Y.; Nomura, S.; Ikeda, T.; Seki, M.; Kamachi, M. Characterization of Unimolecular Micelles of Random Copolymers of Sodium 2-(Acrylamido)-2-Methylpropanesulfonate and Methacrylamides Bearing Bulky Hydrophobic Substituents. Macromolecules 1995, $28,2874-2881$.

(17) Akagi, T.; Piyapakorn, P.; Akashi, M. Formation of Unimer Nanoparticles by Controlling the Self-Association of Hydrophobically Modified Poly(Amino Acid)S. Langmuir 2012, 28, 5249-5256.

(18) Terashima, T.; Sugita, T.; Fukae, K.; Sawamoto, M. Synthesis and Single-Chain Folding of Amphiphilic Random Copolymers in Water. Macromolecules 2014, 47, 589-600.

(19) Liu, R. C. W.; Pallier, A.; Brestaz, M.; Pantoustier, N.; Tribet, C. Impact of Polymer Microstructure on the Self-Assembly of Amphiphilic Polymers in Aqueous Solutions. Macromolecules 2007, 40, 4276-4286.

(20) Pomposo, J. A.; Perez-Baena, I.; Lo Verso, F.; Moreno, A. J.; Arbe, A.; Colmenero, J. How Far Are Single-Chain Polymer Nanoparticles in Solution from the Globular State? ACS Macro Lett. 2014, 3, 767-772.

(21) ter Huurne, G. M.; Vantomme, G.; van den Bersselaar, B. W. L.; Thota, B. N. S.; Voets, I. K.; Palmans, A. R. A.; Meijer, E. W. The Effect of Dendritic Pendants on the Folding of Amphiphilic Copolymers via Supramolecular Interactions. J. Polym. Sci. Part A Polym. Chem. 2019, 57, 411-421.

(22) Formanek, M.; Moreno, A. J. Effects of Precursor Topology and Synthesis under Crowding Conditions on the Structure of SingleChain Polymer Nanoparticles. Soft Matter 2017, 13, 6430-6438.

(23) Zhang, J.; Tanaka, J.; Gurnani, P.; Wilson, P.; Hartlieb, M.; Perrier, S. Self-Assembly and Disassembly of Stimuli Responsive Tadpole-like Single Chain Nanoparticles Using a Switchable Hydrophilic/Hydrophobic Boronic Acid Cross-Linker. Polym. Chem. 2017, $8,4079-4087$.

(24) Terashima, T.; Mes, T.; de Greef, T. F. A.; Gillissen, M. A. J.; Besenius, P.; Palmans, A. R. A.; Meijer, E. W. Single-Chain Folding of Polymers for Catalytic Systems in Water. J. Am. Chem. Soc. 2011, 133, $4742-4745$.

(25) Stals, P. J. M.; Gillissen, M. A. J.; Paffen, T. F. E.; de Greef, T. F. A.; Lindner, P.; Meijer, E. W.; Palmans, A. R. A.; Voets, I. K. Folding Polymers with Pendant Hydrogen Bonding Motifs in Water: The Effect of Polymer Length and Concentration on the Shape and Size of Single-Chain Polymeric Nanoparticles. Macromolecules 2014, 47, 2947-2954.

(26) Stals, P. J. M.; Gillissen, M. A. J.; Nicolaÿ, R.; Palmans, A. R. A.; Meijer, E. W. The Balance between Intramolecular Hydrogen Bonding, Polymer Solubility and Rigidity in Single-Chain Polymeric Nanoparticles. Polym. Chem. 2013, 4, 2584-2597.

(27) ter Huurne, G. M.; de Windt, L. N. J.; Liu, Y.; Meijer, E. W.; Voets, I. K.; Palmans, A. R. A. Improving the Folding of Supramolecular Copolymers by Controlling the Assembly Pathway Complexity. Macromolecules 2017, 50, 8562-8569.

(28) Zhang, Y.; Tan, R.; Gao, M.; Hao, P.; Yin, D. Bio-Inspired Single-Chain Polymeric Nanoparticles Containing a Chiral Salen TiIV Complex for Highly Enantioselective Sulfoxidation in Water. Green Chem. 2017, 19, 1182-1193. 
(29) Chen, J.; Wang, J.; Bai, Y.; Li, K.; Garcia, E. S.; Ferguson, A. L.; Zimmerman, S. C. Enzyme-like Click Catalysis by a CopperContaining Single-Chain Nanoparticle. J. Am. Chem. Soc. 2018, 140, 13695-13702.

(30) Zhang, Y.; Wang, W.; Fu, W.; Zhang, M.; Tang, Z.; Tan, R.; Yin, D. Titanium(Iv)-Folded Single-Chain Polymeric Nanoparticles as Artificial Metalloenzyme for Asymmetric Sulfoxidation in Water. Chem. Commun. 2018, 54, 9430-9433.

(31) Liu, Y.; Pujals, S.; Stals, P. J. M.; Paulöhrl, T.; Presolski, S. I.; Meijer, E. W.; Albertazzi, L.; Palmans, A. R. A. Catalytically Active Single-Chain Polymeric Nanoparticles: Exploring Their Functions in Complex Biological Media. J. Am. Chem. Soc. 2018, 140, 3423-3433.

(32) Chen, J.; Wang, J.; Li, K.; Wang, Y.; Gruebele, M.; Ferguson, A. L.; Zimmerman, S. C. Polymeric "Clickase" Accelerates the Copper Click Reaction of Small Molecules, Proteins, and Cells. J. Am. Chem. Soc. 2019, 141, 9693-9700.

(33) Kröger, A. P. P.; Hamelmann, N. M.; Juan, A.; Lindhoud, S.; Paulusse, J. M. J. Biocompatible Single-Chain Polymer Nanoparticles for Drug Delivery: a Dual Approach. ACS Appl. Mater. Interfaces 2018, 10, 30946-30951.

(34) Cheng, C. C.; Huang, S. Y.; Fan, W. L.; Lee, A. W.; Chiu, C. W.; Lee, D. J.; Lai, J. Y. Water-Soluble Single-Chain Polymeric Nanoparticles for Highly Selective Cancer Chemotherapy. ACS Appl. Polym. Mater. 2021, 3, 474-484.

(35) Fan, W.; Tong, X.; Farnia, F.; Yu, B.; Zhao, Y. CO2-Responsive Polymer Single-Chain Nanoparticles and Self-Assembly for GasTunable Nanoreactors. Chem. Mater. 2017, 29, 5693-5701.

(36) Perez-Baena, I.; Loinaz, I.; Padro, D.; García, I.; Grande, H. J.; Odriozola, I. Single-Chain Polyacrylic Nanoparticles with Multiple Gd(Iii) Centres as Potential MRI Contrast Agents. J. Mater. Chem. 2010, 20, 6916-6922.

(37) Collot, M.; Schild, J.; Fam, K. T.; Bouchaala, R.; Klymchenko, A. S. Stealth and Bright Monomolecular Fluorescent Organic Nanoparticles Based on Folded Amphiphilic Polymer. ACS Nano 2020, 14, 13924-13937.

(38) Photos, P. J.; Bacakova, L.; Discher, B.; Bates, F. S.; Discher, D. E. Polymer Vesicles in Vivo: Correlations with PEG Molecular Weight. J. Control. Release 2003, 90, 323-334.

(39) Auría-Soro, C.; Nesma, T.; Juanes-Velasco, P.; LandeiraViñuela, A.; Fidalgo-Gomez, H.; Acebes-Fernandez, V.; Gongora, R.; Parra, M. J. A.; Manzano-Roman, R.; Fuentes, M. Interactions of Nanoparticles and Biosystems: Microenvironment of Nanoparticles and Biomolecules in Nanomedicine. Nanomaterials 2019, 9, 13651385.

(40) Walkey, C. D.; Chan, W. C. W. Understanding and Controlling the Interaction of Nanomaterials with Proteins in a Physiological Environment. Chem. Soc. Rev. 2012, 41, 2780-2799.

(41) Obst, K.; Yealland, G.; Balzus, B.; Miceli, E.; Dimde, M.; Weise, C.; Eravci, M.; Bodmeier, R.; Haag, R.; Calderón, M.; Charbaji, N.; Hedtrich, S. Protein Corona Formation on Colloidal Polymeric Nanoparticles and Polymeric Nanogels: Impact on Cellular Uptake, Toxicity, Immunogenicity, and Drug Release Properties. Biomacromolecules 2017, 18, 1762-1771.

(42) Azagarsamy, M. A.; Yesilyurt, V.; Thayumanavan, S. Disassembly of Dendritic Micellar Containers Due to Protein Binding. J. Am. Chem. Soc. 2010, 132, 4550-4551.

(43) Cao, Z. T.; Gan, L. Q.; Jiang, W.; Wang, J. L.; Zhang, H. B.; Zhang, Y.; Wang, Y.; Yang, X.; Xiong, M.; Wang, J. Protein Binding Affinity of Polymeric Nanoparticles as a Direct Indicator of Their Pharmacokinetics. ACS Nano 2020, 14, 3563-3575.

(44) Mes, T.; van der Weegen, R.; Palmans, A. R. A.; Meijer, E. W. Single-Chain Polymeric Nanoparticles by Stepwise Folding. Angew. Chem. Int. Ed. 2011, 50, 5085-5089.

(45) Rogers, D. M.; Jasim, S. B.; Dyer, N. T.; Auvray, F.; Réfrégiers, M.; Hirst, J. D. Electronic Circular Dichroism Spectroscopy of Proteins. Chem 2019, 5, 2751-2774.

(46) Miles, A. J.; Wallace, B. A. Circular Dichroism Spectroscopy of Membrane Proteins. Chem. Soc. Rev. 2016, 45, 4859-4872.
(47) Liu, J.; Zeng, F.; Allen, C. Influence of Serum Protein on Polycarbonate-Based Copolymer Micelles as a Delivery System for a Hydrophobic Anti-Cancer Agent. J. Control. Release 2005, 103, 481497.

(48) Lu, J.; Owen, S. C.; Shoichet, M. S. Stability of Self-Assembled Polymeric Micelles in Serum. Macromolecules 2011, 44, 6002-6008.

(49) Sahu, A.; Kasoju, N.; Bora, U. Fluorescence Study of the Curcumin-Casein Micelle Complexation and Its Application as a Drug Nanocarrier to Cancer Cells. Biomacromolecules 2008, 9, 2905-2912.

(50) Torchilin, V. P. Fluorescence Microscopy to Follow the Targeting of Liposomes and Micelles to Cells and Their Intracellular Fate. Adv. Drug Deliv. Rev. 2005, 57, 95-109.

(51) Feiner-Gracia, N.; Buzhor, M.; Fuentes, E.; Pujals, S.; Amir, R. J.; Albertazzi, L. Micellar Stability in Biological Media Dictates Internalization in Living Cells. J. Am. Chem. Soc. 2017, 139, 1667716687.

(52) Reichardt, C. Solvatochromic Dyes as Solvent Polarity Indicators. Chem. Rev. 1994, 94, 2319-2358.

(53) Klymchenko, A. S. Solvatochromic and Fluorogenic Dyes as Environment-Sensitive Probes: Design and Biological Applications. Acc. Chem. Res. 2017, 50, 366-375.

(54) Kucherak, O. A.; Oncul, S.; Darwich, Z.; Yushchenko, D. A.; Arntz, Y.; Didier, P.; Mély, Y.; Klymchenko, A. S. Switchable Nile Red-Based Probe for Cholesterol and Lipid Order at the Outer Leaflet of Biomembranes. J. Am. Chem. Soc. 2010, 132, 4907-4916.

(55) Lee, H.; Choi, M. G.; Yu, H. Y.; Ahn, S.; Chang, S. K. Selective Mercuration of 2-Hydroxy Nile Red and Its Application towards Chemodosimetric Hg2+-Selective Signaling. Bull. Korean Chem. Soc. 2010, 31, 3539-3542.

(56) De Schutter, C.; Roy, V.; Favetta, P.; Pavageau, C.; Maisonneuve, S.; Bogliotti, N.; Xie, J.; Agrofoglio, L. A. Synthesis and Characterization of Various 5'-Dye-Labeled Ribonucleosides. Org. Biomol. Chem. 2018, 16, 6552-6563.

(57) Eberhardt, M.; Mruk, R.; Zentel, R.; Théato, P. Synthesis of Pentafluorophenyl(Meth)Acrylate Polymers: New Precursor Polymers for the Synthesis of Multifunctional Materials. Eur. Polym. J. 2005, 41, 1569-1575.

(58) Stuart, M. C. A.; Van De Pas, J. C.; Engberts, J. B. F. N. The Use of Nile Red to Monitor the Aggregation Behavior in Ternary Surfactant-Water-Organic Solvent Systems. J. Phys. Org. Chem. 2005, 18, 929-934.

(59) Greene, R. F.; Pace, C. N. Urea and Guanidine Hydrochloride Denaturation of Ribonuclease, Lysozyme, $\alpha$ Chymotrypsin, and $\beta$ Lactoglobulin. J. Biol. Chem. 1974, 249, 5388-5393.

(60) Huerta-Viga, A.; Woutersen, S. Protein Denaturation with Guanidinium: A 2D-IR Study. J. Phys. Chem. Lett. 2013, 4, 33973401.

(61) Romanchuk, K. G. Fluorescein. Physicochemical Factors Affecting Its Fluorescence. Surv. Ophthalmol. 1982, 26, 269-283.

(62) Gillissen, M. A. J.; Terashima, T.; Meijer, E. W.; Palmans, A. R. A.; Voets, I. K. Sticky Supramolecular Grafts Stretch Single Polymer Chains. Macromolecules 2013, 46, 4120-4125.

(63) Andrian, T.; Riera, R.; Pujals, S.; Albertazzi, L. Nanoscopy for Endosomal Escape Quantification. Nanoscale Adv. 2021, 3, 10-23.

(64) Albertazzi, L.; Storti, B.; Marchetti, L.; Beltram, F. Delivery and Subcellular Targeting of Dendrimer-Based Fluorescent $\mathrm{pH}$ Sensors in Living Cells. J. Am. Chem. Soc. 2010, 132, 18158-18167.

(65) Shi, J.; Ma, Y.; Zhu, J.; Chen, Y.; Sun, Y.; Yao, Y.; Yang, Z.; Xie, J. A Review on Electroporation-Based Intracellular Delivery. Molecules 2018, 23, 3044-3063.

(66) Elsabahy, M.; Wooley, K. L. Design of Polymeric Nanoparticles for Biomedical Delivery Applications. Chem. Soc. Rev. 2012, 41, $2545-2561$ 